\title{
Explaining CDS prices with Merton's model before and after the Lehman default
}

\section{Article}

\section{Accepted Version}

Creative Commons: Attribution-Noncommercial-No Derivative Works 4.0

Gemmill, G. and Marra, M. (2019) Explaining CDS prices with Merton's model before and after the Lehman default. Journal of Banking and Finance, 106. pp. 93-109. ISSN 1872-6372 doi: https://doi.org/10.1016/j.jbankfin.2019.05.013 Available at https://centaur.reading.ac.uk/83796/

It is advisable to refer to the publisher's version if you intend to cite from the work. See Guidance on citing.

To link to this article DOI: http://dx.doi.org/10.1016/j.jbankfin.2019.05.013

Publisher: Elsevier

All outputs in CentAUR are protected by Intellectual Property Rights law, including copyright law. Copyright and IPR is retained by the creators or other copyright holders. Terms and conditions for use of this material are defined in the End User Agreement.

\section{www.reading.ac.uk/centaur}

\section{CentAUR}

Central Archive at the University of Reading

Reading's research outputs online 


\title{
Explaining CDS Prices With Merton's Model Before and After the Lehman Default
}

\author{
Gordon Gemmill*and Miriam Marra ${ }^{\dagger}$
}

This Version: May 20, 2019

\begin{abstract}
We examine whether CDS prices around the Credit Crisis can be explained with Merton's model. First we invert the model with market prices to reveal skewed volatility smiles over the whole 2005-2012 period. Then we calibrate the model to pre-Crisis data in two novel ways that allow for skewness, one based on equity-index options (MEIV) and the other on the sensitivity of CDS prices to equity volatility (MSKEW). In out-of-sample forecasts both calibrations match the in-Crisis peak of prices, but the second is better at capturing the systematic component of prices thereafter. Average CDS prices remain at twice their pre-Crisis level long after that event; the MSKEW calibration demonstrates that this is due to extra idiosyncratic risks, which are important for some firms but have negligible impact on others.
\end{abstract}

JEL classification: G1, G12, G19.

Keywords: Credit Default Swap; Merton's Model; Volatility Smile; Credit Crisis; Idiosyncratic Risk.

\footnotetext{
*Corresponding Author: Warwick Business School, University of Warwick, Coventry, UK (Email: G.T.Gemmill@warwick.ac.uk)

${ }^{\dagger}$ ICMA Centre, Henley Business School, University of Reading, UK (Email: m.marra@icmacentre.ac.uk). The authors thank Ron Anderson, Menachem Brenner, Aparna Gupta, Hayne Leland, Francis Longstaff, Ian Marsh, Anthony Neuberger, Paul Schneider, Christian Wagner and three anonymous referees for valuable comments and suggestions.
} 


\section{Introduction}

The aim of this paper is to examine whether Merton's (1974) debt model, suitably calibrated for the time-varying skewness of asset returns in the risk-neutral domain, can explain the behaviour of CDS prices before and after the Credit Crisis. The dramatic market conditions after the Lehman default of September 2008 provide a unique opportunity to examine the performance of the model, because CDS prices and their causal variables (such as equity volatility) have a very wide range of values over this period.

To set the context, Figure 1 plots mean and median CDS prices for our sample of 40 investment-grade companies from the beginning of 2005 to the end of 2012. The vertical line in the middle of the plot indicates the time of the Lehman default in September 2008. The mean price (continuous, upper line) is quite stable at less than 50 basis points over 2005 to 2007 but then doubles temporarily to 100 basis points in March 2008 when Bear Stearns collapses. After the Lehman default in September 2008 there is a further doubling of the mean price to about 200 basis points, followed by a fall back to a range of 80 to 110 basis points which is maintained through to the end of 2012 . The median price (dotted, lower line) is very close to the mean until the first signs of the Crisis appear in 2008, after which the median is 20 to 100 basis points lower than the mean.

Some questions to be addressed in the paper are prompted by these plots. First, is the large increase in CDS prices after the Lehman default justified, given the dynamics of CDS prices and key structural model variables in the earlier period? Second, why do prices remain at least twice as high in 20102012 as they were in 2005-2007? And third, why is the mean price much higher than the median after the Crisis, when it was not higher before? Our use of the Merton model will help to answer these questions.

The paper begins by showing that implied volatilities for the cross-section of CDSs display a welldefined 'smile' when plotted against leverage. This is reminiscent of the skewed smile found for put options on equity indices when using the Black/Scholes model (see, for example, Bollen and Whaley, 2004). As in that case, the skewness of the smile suggests that downside risk is priced into investment-grade CDSs: investors take into account the likelihood of catastrophic events, which

make these CDS contracts 'expensive'. Before the Lehman default, all firms at a given leverage tend to have the same implied asset volatility, indicating that most risk is considered to be common to all 
of them (i.e. is systematic). After the Lehman default, the smile remains clearly visible but it shifts upwards and there is much more individual (i.e. idiosyncratic) variation across firms.

Having observed the empirical regularity of the volatility smile, we turn our attention to developing a method for fitting Merton-style models that can incorporate this feature, i.e. a model that allows for a fat tail in the risk-neutral distribution of firm value. Our focus is not so much on why the tail is fat and CDS prices are so large, a feature known as the 'credit spread puzzle', but on modeling how this puzzle changes over time.

The traditional approach to modelling of the CDS price $(S)$ of a firm is to calibrate a Merton (structural) model to a historic estimate of the firm's asset volatility $\left(\sigma_{A}\right)$, the latter being derived from the firm's equity volatility $\left(\sigma_{E}\right)$. However, this traditional approach leads to CDS prices that are close to zero under normal market conditions, because it fits a physical distribution which has low skewness relative to the risk-neutral distribution.

Instead we use two different approaches to calibrate the model to the risk-neutral distribution and then compare their performances with the traditional one. The first approach makes use of the relationship between the volatility smiles of equity-index options and the volatility smiles of CDS contracts. If the equity-index smile reflects the skewness of the distribution of the share price for a representative firm, then such skewness should also appear in the distribution of the firm's asset value and generate a CDS smile. We project the equity smile to the CDS market, using pre-Crisis data for the calibration, and make post-Crisis forecasts that change as the equity smile changes. We denote this approach as the Merton Equity Implied Volatility (MEIV) calibration.

The second calibration is based on the sensitivity of CDS prices to equity volatility $\left(\partial S / \partial \sigma_{E}\right)$, which may be contrasted with the traditional approach of calibrating directly to equity volatility $\left(\sigma_{E}\right){ }^{1}$ A time-varying equation for $\partial S / \partial \sigma_{E}$ is specified for the calibration in the pre-Crisis period. The equation allows $\partial S / \partial \sigma_{E}$ to rise when either market volatility or individual-firm volatility rises, thus generating time-series variation in CDS prices. We denote this approach as the Merton Skewed (MSKEW) calibration.

Before the Lehman default (in-sample), both calibrations fit the data well, generating smiles that

1 This new method of calibration is possible because $\partial S / \partial \sigma_{E}$ is monotonically related to the equity volatility of the firm (as we show in Appendix A.3). The relationship between $\partial S / \partial \sigma_{E}$ and the credit spread from Merton's model has been noted in passing by Campbell and Taksler (2003) and by Gemmill and Keswani (2011), but we are the first to employ it for explaining the time-series and cross-section features of CDS prices. 
are close to those observed empirically. Moreover, after the Lehman default (out-of-sample), both calibrations forecast the peak of CDS prices at the end of November 2008. However from mid2009 onwards, when calmer conditions return, the two calibrations give rather different forecasts. Although they generate volatility smiles with similar shapes, those of the MSKEW lie below those of the MEIV. The MSKEW smiles follow a lower bound, capturing the systematic component of prices but ignoring the increase in idiosyncratic risks that now raise CDS prices for some firms but not for others.

The final part of the paper investigates the character of the idiosyncratic risks that cause market prices to differ from MSKEW forecasts in the post-Crisis period. A multivariate analysis reveals that liquidity, earnings uncertainty and rating all contribute to the higher average level of post-Crisis CDS prices. The conclusion is that idiosyncratic risks, that were of relatively little importance before the Crisis, become permanently more important (for the setting of CDS prices) after that event.

The main contributions of our paper are threefold: first, we demonstrate the existence of volatility smiles in the cross-section of CDS prices; second, we show how Merton's model can be calibrated in two simple ways to take account of these smiles (which reflect the skewed risk-neutral distribution of firm value); and third, the calibrated models reveal that CDS prices are not excessive during the Crisis, but remain higher than expected thereafter because firm-specific factors now play a much more important role that they did before.

The paper is written as follows. Section 2 outlines the data that we use. Section 3 introduces the Merton model (1974) and explains the two calibrations. Section 4 discusses the forecasts made with those calibrations and how they compare with market values. Section 5 draws together the conclusions of the study.

\section{Data Sample}

We focus our study on U.S. dollar-denominated CDS contracts with five years to maturity, as they are the most liquid. To ensure continuous availability of CDS data, we take the 125 firms that are listed in the CDX North American Investment Grade Index (CDX.NA.IG) at the beginning of 2005, but eliminate those firms that have dropped out from the Index in the subsequent years (until 2012). We also eliminate all financial, insurance, and real-estate firms, due to the difficulty of interpreting 
their capital-structure variables. There remain forty firms in the sample. This is less than in studies that use short periods with discontinuous series (such as Arora, Bohn and Zu, 2005; Bao, 2009; and Bao and Pan, 2013), but similar to other studies that require continuous data (such as Christoffersen, Ericsson, Jacobs and Jin, 2009, and Du, Elkamhi and Ericsson, 2018). CDS data on prices and quotes are collected from Markit and checked against Bloomberg prices and quotes for the period January 2005 to December 2012. Firms with a large number of missing data are eliminated. The 1st and 99th percentiles of CDS quotes are winsorized in order to eliminate potential outliers. ${ }^{2}$

Although CDS prices are available on a daily basis, we use weekly averages so that the impact of outliers and measurement errors is reduced (for example due to CDS bid-ask spreads). Our final dataset contains prices and quotes for CDSs of 40 U.S. investment-grade firms over the 418 weeks from 2 January 2005 to 30 December 2012, giving (after omissions) a total of 16476 observations. A full list of the firms is given in Appendix B.

Table 1 gives information on the CDS prices and some of the variables that may influence them. The table is separated into the pre-Crisis period, from 1st January 2005 up to the week of $7^{\text {th }}$ September 2008, (to be used for calibration of the model), the Crisis period of weeks from $14^{\text {th }}$ September 2008 to $31^{\text {st }}$ December 2009, and the post-Crisis period of weeks from $1^{\text {st }}$ January 2010 to the end of 2012. The average CDS prices are 40 basis points in the first period, rise to 124 points during the Crisis and only fall back to 93 basis points in the third period. Equity volatilities and the S\&P volatility move together: they start at annualized average values of $23 \%$ and $14 \%$ respectively in the first period and rise to $40 \%$ and $38 \%$ in the Crisis period. Unlike the average CDS prices, the volatilities then fall back to levels in the third period that are not far above those in the first period, i.e. $24 \%$ and $19 \%$ respectively. Leverage at date of observation is quite low for the sampled firms, reflecting their investment grade, starting at an average of $13 \%$, then rising to $21 \%$ in the Crisis and finishing at $18 \%$ in the third period. Note however that there is a wide range of leverage in each period, for example from $2 \%$ to $47 \%$ across firms in the first period. The risk-free rate averages $3.7 \%$ in the first period, but then falls close to zero during the Crisis and post-Crisis periods. The firms in the sample are large, averaging about $\$ 20$-30 billion across periods, but again there is quite a wide range: for example, they vary from $\$ 3$ billion to $\$ 177$ billion in the first period.

Table 2 gives the ratings for firms, separated once again into Pre-Crisis, Crisis and Post-Crisis periods.

\footnotetext{
${ }^{2}$ Mayordomo, Pena and Schwartz (2014) caution that there are significant differences between CDS prices from different sources, but we do not find large differences between Markit and Bloomberg prices for our sample of firms.
} 
The effect of the Crisis on ratings is rather modest, which is consistent with agencies that try to 'rate through the cycle' in order to achieve stability in credit ratings. $65 \%$ of firms are rated between A and $\mathrm{BBB}+$ in the Pre-Crisis Period, $62 \%$ remain in that range during the Crisis, and $60 \%$ after the Crisis. The firms are all of investment-grade when the sample starts, for which the minimum rating is normally BBB-, but one firm falls to BB+ during the Pre-Crisis period, two firms are at that level during the Crisis and these two remain at that level for most of the Post-Crisis period. At the top end, there are firms of $\mathrm{A}+$ or better in all periods.

\section{The Merton Model and Implied Fat Tails}

\subsection{The Merton Model (1974)}

Merton's model is based on the idea that equity and debt are contingent claims on a firm's assets. As in Black and Scholes (1973), the claims are valued under the assumption that there are no impediments to arbitrage. Let the firm's assets $(A)$ follow a lognormal diffusion process with growth rate $\mu$ and volatility $\sigma_{A}$ :

$$
d A_{t}=\mu A_{t} d t+\sigma_{A} A_{t} d W_{t}
$$

where $W$ is a Brownian motion. The firm's liabilities consist of a risky zero-coupon bond $B$ (with face value $D$ and maturity $T$ ) and equity $E$. The firm's leverage $L$ is defined here as the ratio between the present value of the bond's promised payment $D$ and the total value of the assets $A$. Thus, we have $L=\frac{D e^{-r T}}{A}$. Default can only occur at maturity $T$ if $A_{T}<D$.

Merton (1974) values the risky bond as a contingent claim written on the firm's assets. The bond is equivalent to a combination of a long position in a riskless bond and a short position in a European put option written on the firm's assets (with strike-price equal to the bond's face value, $D$ ). When volatility increases, the value of the put option increases and the bond price falls, increasing the bond's yield. The credit spread is the difference between the risky bond yield $(y)$ and the risk-free rate $(r)$. As shown in Appendix A.1, Merton's expression for the credit spread $(S)$ can be written as

$$
S=y-r=-\frac{1}{T} \ln \left[N\left(d_{2}\right)+\frac{N\left(-d_{1}\right)}{L}\right]
$$

The variables in equation (2) that affect the spread are the asset volatility $\left(\sigma_{A}\right)$, the leverage $(L)$ 
where $\quad \begin{aligned} d_{1} & =\frac{-\ln (L)}{\sigma_{A} \sqrt{T}}+\frac{\sigma_{A} \sqrt{T}}{2} \\ d_{2} & =d_{1}-\sigma_{A} \sqrt{T}\end{aligned}$

and $\quad N(x)$ is the probability from a standard-normal distribution of $x$.

and the time to maturity of the debt $(T) .^{3}$

The extra yield on a risky bond, the credit spread, is a payment to compensate for the probability of default. Similarly, a riskless bond can be replicated by a long position on a risky bond plus a CDS contract. The CDS contract is a put option on the firm's assets and the CDS premium is equal to the credit spread. If Merton's model can be applied to credit spreads then it can also be applied to CDS prices (as has been done by Huang and Zhou, 2008, for example). ${ }^{4}$

\subsection{Evidence of Fat Tails}

One of the main limitations of Merton's standard model is the lognormality assumption, according to which the risk-neutral distribution of the firm value has only a small left-hand tail. It follows that put options written on the firm should also have small values, particularly when a firm has low leverage and the put is deep-out-of-the-money. The result is that CDS prices computed with Merton's model for investment-grade firms are often close to zero and more sophisticated versions of this model do not perform much better (e.g. Geske, 1979, Longstaff and Schwartz, 1995, Leland and Toft, 1996, Collin-Dufresne and Goldstein, 2001). The literature defines this result as 'the credit spread puzzle' (see, amongst others, Eom, Helwege and Huang, 2004, and Huang and Huang, 2002, 2012 for tests on bond credit spreads, Arora, Bohn, and Zhu, 2005, and Huang and Zhou, 2008, for tests on CDS spreads, and Bao, 2009 and Bao and Pan, 2013, for tests on both bond and CDS spreads).

By contrast, there are many papers which suggest that the risk-neutral distribution of firm value is not lognormal but has a fat left-hand tail. For example, Campbell and Taksler (2003) find that the strength of the positive relationship between equity volatility and credit spreads is far greater than can be explained by a simple implementation of the Merton model. ${ }^{5}$ Incorporating a fat tail into a

\footnotetext{
${ }^{3}$ There is no payout rate in the formula, because the debt is assumed to be a zero-coupon bond. In our formulation later in this paper, a stationary leverage ratio is assumed which also makes the payout rate on the debt irrelevant. ${ }^{4}$ CDS prices have several advantages over yield spreads for empirical studies: first, CDS prices are not affected by differential tax treatments; second, CDS contracts are likely to be more liquid than corporate bonds, which became extremely illiquid during the Credit Crisis (Dick-Nielsen, Feldhütter and Lando, 2012); and third, CDS prices for investment-grade firms are widely reported.

${ }^{5}$ Many empirical studies investigate the importance of equity volatility for credit spreads but they disagree on its magnitude (see, amongst others, Avramov et al., 2007; Benkert, 2004; Gemmill and Keswani, 2011; Chen, Lesmond and Wei, 2007; and Bharath and Shumway, 2008). Campbell and Taksler (2003) find a very large effect, probably because they use very short-lived transactions prices, whereas others find much smaller effects. Doshi, Ericsson, Jacobs
} 
structural model might lead to better predictions of credit spreads, particularly for investment-grade bonds at short maturities (Delianedis and Geske, 2001; Zhou, 2001; Leland, 2009).

Empirical evidence of a fat tail in the risk-neutral distribution can most easily be seen as a volatility smile. ${ }^{6}$ If the Merton model is applied to CDS prices in cross section, the implied asset volatilities when plotted against leverage display a strong smile. This is illustrated in Figure 2 with plots in March of each year across the eight years of our sample. A logarithmic curve is fitted to each week's data. Note that the leverage here, and in the rest of this paper, is a value projected to CDS maturity, as will be explained in section 3.3 below. Looking across the upper four plots, representing the preCrisis sample, the smile is well-defined but with individual firms' implied volatilities becoming a little more scattered as we move from March 2005 to March 2008. A measure of the widening scatter around the curve is the declining $\mathrm{R}^{2}$ value, starting at 0.91 in March 2005 and falling to 0.62 in March 2008. Turning to the lower four plots (the post-Crisis period), the smile remains clear but the scatter is now much larger than before. In particular in March 2009, which is a very unstable period, the scatter is such that the $\mathrm{R}^{2}$ is only 0.21 . Thereafter the scatter becomes narrower, with $\mathrm{R}^{2}$ in the range of 0.50 to 0.71 for the three weeks in 2010, 2011 and 2012 plotted in the figure.

An interesting initial finding of this paper is therefore that the pattern of implied asset volatilities from CDS contracts is very systematic in leverage, i.e. implied volatilities for firms with similar leverage cluster together. This suggests that tail events are not perceived by investors as relating to individual firms, but are triggered by the fear of a catastrophic default across all firms, as discussed by Coval, Jurek and Stafford (2009). ${ }^{7}$ It follows that what is most important for the pricing of CDS contracts of investment-grade firms is market-wide systematic risk, rather than the idiosyncratic risk of any individual firm. To a first approximation, the same shape of risk-neutral distribution for firm value may be applied to all investment-grade firms. ${ }^{8}$ Nevertheless, the increasing scatter after the Lehman default in Figure 2 indicates that firm-specific risk becomes more important for prices as

and Turnbull (2013) relate default intensity to equity volatility, leverage, and the term-structure of interest rates; the large contribution of equity volatility is again confirmed. Chen, Chidambaran, Imerman and Sopranzetti (2014) find the default probability of Lehman Brothers through time, using similar variables in a structural model.

${ }^{6}$ If there were an equity price with a lognormal distribution, there would be no smile for equity options but there would be a small smile for CDSs or bonds because of the effect of leverage on the distribution of the asset price. The smile in CDS contracts has also very recently been noted independently by Kelly, Manzo and Palhares (2016).

${ }^{7}$ The existing theoretical literature supports this hypothesis. For example, Collin-Dufresne, Goldstein and Helwege (2010) suggest that a credit contagion can result from the "updating of investors' beliefs" on the likelihood of firms' crashes. The contagion may depend on the characteristics of the credit event, the particular company and its industry (see Jorion and Zhang, 2007).

${ }^{8}$ We have verified that this specific pattern is not only a CDS phenomenon by analyzing corporate bond yield spreads for 238 U.S. investment-grade firms on 5 January 2000. (The data source is Bloomberg and we thank Aneel Keswani for providing these data). We find exactly the same kind of implied volatility 'smile' to exist in bond spreads as in CDS prices. 
the Crisis develops.

We can fit a curve to the volatility smile to make it continuous and then invert it to reveal the riskneutral distribution in a particular week. As an example, CDS prices from the week beginning $19^{\text {th }}$ March 2006 (already used for the smile in Figure 2) are used to generate the left tail of the risk-neutral distribution which is plotted in Figure 3. We also plot the tail of a lognormal distribution with a volatility of $17 \%$. The fat tail of the distribution implied from the CDS data (continuous line) is in clear contrast to the thin tail of the lognormal distribution (dashed line). ${ }^{9}$ Consistent with Figure 3, Doshi, Ericsson, Jacobs and Turnbull (2013) have estimated that over 2001 to 2010 the tail of the risk-neutral (Q) distribution for CDS contracts is about four times as large as that of the physical (P) distribution. ${ }^{10}$ This gap between $\mathrm{Q}$ and $\mathrm{P}$ asset distributions is hard for conventionally-estimated models to explain.

\subsection{Fat Tails and the Merton Model}

The next step is to consider how a fat-tailed distribution can be incorporated into a Merton-style model for CDS prices. One way would be to assume that the underlying process for the firm's assets has stochastic volatility and jumps. Such a process can be estimated from high-frequency data on equity prices (e.g. Zhang, Zhou and Zhu, 2009) ${ }^{11}$ or with a GARCH model (e.g. Christoffersen, Jacobs and Ornthanalai, 2013). Equity options and equity-index options can also be used for the estimation. Hull, Nelken and White (2005) use two equity options to infer directly the Merton spread. Cremers, Driessen, Maenhout and Weinbaum (2008) show how implied volatilities relate to bond spreads, while Cremers, Driessen and Maenhout (2009) estimate jump parameters for firm value and bond spreads using both individual and equity-index options. Carr and Wu (2009), Bao (2009), Chen and Kou (2009), Cao, Yu and Zhong (2010), Wang, Zhou and Zhou (2013), Bai and Wu (2016), Kelly, Manzo and Palhares (2016) and Du, Elkamhi and Ericsson (2019) all use equity options (some in more formal ways than others) to estimate the Q distribution and generate credit

\footnotetext{
${ }^{9}$ Because of the limited range of leverage across the 40 firms, the analysis can only reveal the left-hand tail of the implied distribution. A $17 \%$ volatility is used for the lognormal distribution as that is the volatility computed with the method of Schaefer and Strebulaev (2008) in that week.

${ }^{10}$ Feldhütter and Schaefer (2018) argue that the long-run probability of default has been understated, which can explain the apparent difference between the $\mathrm{Q}$ and $\mathrm{P}$ distributions. Their results may be contrasted with those in Huang and Huang (2012), who attribute very little of the credit spread to the shorter-term probability of default.

${ }^{11}$ There is also a large parallel literature on the character of the asset-price process which could generate large out-ofthe-money put values on equity indices (see e.g. Broadie, Chernov and Johannes, 2009).
} 
spreads. $^{12}$

We prefer to take two more simple approaches to calibrating the observed Q distribution. The first of these (Merton Equity Implied Volatility, MEIV) is based on relating the Q distribution for CDS contracts to the $\mathrm{Q}$ distribution for contemporaneous equity-index options, using volatility smiles for that projection. It assumes that idiosyncratic factors do not affect the CDS prices of different firms, consistent with the well-defined volatility smiles that we have already observed across firms before the Lehman default. Our second approach to calibration (Merton Skewed, MSKEW) is to connect the $\mathrm{Q}$ and $\mathrm{P}$ distributions by estimating the sensitivity of each firm's CDS price ( $\mathrm{Q}$ domain) to both the volatility of its own equity and the volatility of the equity index (both $\mathrm{P}$ domain).

Instead of assuming that leverage declines over time, as is implicit in the conventional Merton model because of the drift in the asset price at the risk-free rate, we follow Collin-Dufresne and Goldstein (2001) in assuming throughout this paper that leverage is mean-reverting (i.e. there is a stationary leverage ratio). The firm's current leverage is assumed to revert back to $75 \%$ of its long-run value after five years, with the latter measured here as the average leverage over 2005 to 2012 . The $75 \%$ adjustment after five years is based on the results in Flannery and Rangan (2006), which suggest that the annual rate of reversion is somewhere between 51\% per 5-years, with Fama/MacBeth estimation, and $88 \%$ per 5 -years, with panel estimation.

The MEIV and MSKEW calibrations will now be explained in more detail.

\subsection{The MEIV Calibration}

Implied volatilities for S\&P500 index options (SPX) are obtained from OptionMetrics for each Wednesday over the period January 2005 to December 2012. Taking two option maturities near to 9 months with large numbers of exercise prices, a 9-month 'constant maturity' smile is generated for each day by interpolation. We choose 9 months because it is a maturity around which there are liquid and well-reported options with slightly longer and slightly shorter maturities. The relationship between the 9-month equity smile of the index and the 5-year asset smile of the CDS contracts is then estimated for the pre-Lehman period. This is done in two steps.

First, the equity smile is projected with a logarithmic function to the moneyness (leverage) of the

${ }^{12}$ Coval, Jurek, and Stafford (2009) and Collin-Dufresne, Goldstein, and Yang (2012) extend this insight to the pricing of bundles of CDS contracts, i.e. to the pricing of CDO tranches. 
CDS contracts. Coval, Jurek and Stafford (2009) make projections in a rather similar way when calibrating Merton's model to CDS indices, although they are not very explicit, and Culp, Nozawa and Veronesi (2018) examine bond spreads that would arise for firms that held assets replicating the equity index.

Second, a proportional adjustment is estimated for shifting the projected equity smile down to the CDS smile. The only parameter to be estimated is therefore the proportional shift $(\theta)$ to be applied to the projected equity smile in order to replicate the CDS smile. We expect $\theta<1$ for two reasons: first, 5-year options have lower implied volatilities than 9-month options (Derman, Kani and Zhou, 1996); and second, asset volatilities are less than equity volatilities (Jones, Mason and Rosenfeld, 1984). A simple average for $\theta$ is found for the pre-Lehman period and then used for the out-of-sample forecasts of the CDS volatility smile. We find the average $\theta$ to be 0.653 , with a standard error of 0.0041. The small standard error indicates that the value of $\theta$ is very stable in the pre-Lehman period. ${ }^{13}$ To summarise this methodology, for each week the 9-month SPX smile is used to project the 5-year CDS smile, based on a logarithmic curve for the SPX smile and a proportional adjustment factor of $\theta=0.653$.

As an example, Figure 4 plots for $19^{\text {th }}$ March 2006 the observed CDS and S\&P smiles, together with the projected S\&P smile and the MEIV smile (obtained from the S\&P smile after the proportional shift). The vertical axis is the implied volatility and the horizontal axis is moneyness (for index options) and leverage (for CDS contracts).

The triangles on the right of the figure are the 9-month implied S\&P-index volatilities for this day. The continuous line at the top left is the logarithmic projection of the 9-month S\&P smile. The continuous line below that is the $\mathrm{S} \& \mathrm{P}$ projection adjusted by the $\theta=0.653$ factor. This line may be compared directly with the observed CDS implied volatilities, which are the cross-shaped points. On this day, which is in-sample, the projected CDS smile is slightly below the observed values (the crosses).

Figure 5 is a plot done similarly for $21^{\text {st }}$ September 2008, which is the week after the Lehman default and therefore an out-of-sample projection. The implied index volatilities on the right (triangles) are higher on this day than before and those on the left for the CDS contracts (crosses) are more

\footnotetext{
$13 \theta$ was also of a very similar magnitude in the post-Lehman sample, having a mean of 0.647 and a standard error of 0.0021. A t-test confirms that $\theta$ did not change between the two periods, even at the $15 \%$ level of significance.
} 
scattered than before around the projected MEIV smile, but the latter (lower left line) is still quite a good approximation of the observed CDS smile. We turn now to our second approach to calibration.

\subsection{The MSKEW Calibration}

The conventional way to calibrate the Merton model is to assume that the asset value $(A)$ can be approximated by the book value of debt $(D)$ plus the market value of equity $(E)$. The asset volatility, $\sigma_{A}$, can then be calculated from the equity volatility, $\sigma_{E}$, using Ito's lemma (Jones, Mason and Rosenfeld, 1984): $:^{14}$

$$
\sigma_{A}=\sigma_{E}(1-L)\left(\frac{1}{\partial E / \partial A}\right)
$$

The MSKEW calibrates Merton's model with the sensitivity of CDS prices to changes in asset volatility $\left(\partial S / \partial \sigma_{A}\right)$, rather than with asset volatility directly. In Appendix A.2 we show that the following equation can be derived within Merton's model, which relates $\partial S / \partial \sigma_{A}$ to asset volatility, leverage and maturity. ${ }^{15}$

$$
\frac{\partial S}{\partial \sigma_{A}}=\frac{N^{\prime}\left(d_{1}\right)}{\sqrt{T}\left[N\left(-d_{1}\right)+L N\left(d_{2}\right)\right]}
$$

where $N^{\prime}\left(d_{1}\right)=\frac{1}{\sqrt{2 \pi}} e^{-0.5 d_{1}^{2}} \cdot{ }^{16}$

We cannot write an explicit equation relating the CDS price $(S)$ to $\partial S / \partial \sigma_{A}$, leverage $(L)$ and maturity $(T)$. Instead, given an estimate for $\partial S / \partial \sigma_{A}$ in a particular week, we iterate over different values of $\sigma_{A}$ until equation (4) is satisfied. ${ }^{17}$ We can then insert the computed asset volatility, $\sigma_{A^{*}}$, into the Merton equation (2) to give a model price for the CDS.

So far we have shown that it is possible to calibrate the Merton model with $\partial S / \partial \sigma_{A}$ instead of

\footnotetext{
${ }^{14} \mathrm{An}$ alternative to using the book value of debt is to estimate simultaneously the asset volatility and the asset value, using an iterative process, such as suggested by Vassalou and Xing (2004), Crosbie et al. (2003), and Bharath and Shumway (2008). Convergence is sometimes a problem.

${ }^{15}$ Note that leverage is approximated here empirically as the ratio of the book value of debt to the sum of the book value of debt plus the market value of equity; this may differ slightly from the present value of debt relative to assets used in Merton's equation (2) above. We thank the referee for making this clarification.

${ }^{16}$ Campbell and Taksler (2003) give a more complicated formulation of this equation. There is a typographic error in their published version which relates to bracketed terms.

${ }^{17}$ There is a monotonic relationship between $\partial S / \partial \sigma_{A}$ and $\sigma_{A}$ over plausible levels of leverage and volatility, as proved in Appendix A.3. That suggests that we can calibrate the Merton model with $\partial S / \partial \sigma_{A}$ instead of calibrating it with $\sigma_{A}$.
} 
calibrating it with $\sigma_{A}$. However, we cannot observe $\partial S / \partial \sigma_{A}$ but only $\partial S / \partial \sigma_{E}$, the sensitivity of the CDS price to equity volatility. We therefore need to relate $\partial \sigma_{A}$ to $\partial \sigma_{E}$. This is accomplished with the leverage adjustment given above at equation (3), which can be re-written in changes (at a given leverage $)^{18}$ as

$$
\partial \sigma_{A}=\partial \sigma_{E}(1-L)\left(\frac{1}{\partial E / \partial A}\right)
$$

For reasons of clarity, we now extend the notation to include domain and horizon. To calibrate the model we want to measure the changes in the asset volatility in the $\mathrm{Q}$ domain at the five-year horizon, $\partial \sigma_{A, Q, 5}$, but we can only observe the changes in the equity volatility in the $\mathrm{P}$ domain at the daily horizon, $\partial \sigma_{E, P, d}$. Equation (3') is used for the equity-to-asset conversion, leaving domain and horizon now to be considered.

With respect to domain, the question is how changes in equity volatility in the $\mathrm{Q}$ domain relate to such changes in the $\mathrm{P}$ domain. We examine this empirically by comparing changes in the volatility index VIX (which are in the Q domain, as they are implied from index options) with changes in the volatility of the S\&P500 Index (which are in the P domain). Using a long series of daily data over 1990-2013, a regression between changes in the two indices has a slope which is not significantly different from unity. ${ }^{19}$ It is therefore reasonable to assume that changes in $\mathrm{Q}$ and $\mathrm{P}$ volatilities are the same, i.e.:

$$
\partial \sigma_{E, Q, d}=\partial \sigma_{E, P, d}
$$

where the extra subscript d denotes a daily measurement.

With respect to horizon, we want to know the relationship between $\partial \sigma_{E, Q, d}$ and $\partial \sigma_{E, Q, 5}$. There is considerable evidence from the literature on volatility surfaces (e.g. Derman, Kani and Zhou, 1996) that long-term options have implied volatilities that are much smaller than those on shortterm options. We compare the daily changes in short-term and long-term implied volatilities for traded options on the 40 companies in our sample over 2005 to 2009. Option data are taken from OptionMetrics. We find that the absolute changes in volatility for one-month options average $0.808 \%$ and for options with at least one year to maturity average $0.396 \%$, a ratio of 2.04 . This result is

${ }^{18}$ Engle and Siriwardane (2014) discuss how the leverage adjustment is increased if the asset-price distribution has a fat tail, which is consistent with our modification of the Merton model (using a local volatility which reflects the size of the fat tail).

${ }^{19}$ Schaefer and Strebulaev (2008) find that Merton's model generates plausible hedge ratios for corporate bonds. That would require that changes in risk-neutral volatilities ( $Q$ domain) are of similar magnitude to changes in physical volatilities ( $\mathrm{P}$ domain), as we have confirmed here. 
similar to that reported by Bakshi, Cao and Chen (2000), who study long-term options on the S\&P500 Index (LEAPS). It is also very similar to the relationship between over-the-counter 1-month and 5-year index options which we have calculated with proprietary data from an investment bank. ${ }^{20}$ Based on this information, we assume that

$$
\partial \sigma_{E, Q, d}=2 \partial \sigma_{E, Q, 5}
$$

Combining equations (3'), (5) and (6), we obtain the following composite adjustment to be made in order to estimate changes in 5-year asset volatilities in the $\mathbf{Q}$ domain, $\partial \sigma_{A, Q, 5}$, from changes in short-term equity volatilities in the $\mathrm{P}$ domain, $\partial \sigma_{E, P, d}$ :

$$
\partial \sigma_{A, Q, 5}=0.5(1-L)\left(\frac{\partial A}{\partial E}\right) \partial \sigma_{E, P, d}
$$

Finally, we need to estimate the sensitivity of CDS premiums to equity volatility, $\frac{\partial S}{\partial \sigma_{E, P, d}}$, in order to calibrate the model with data before the Lehman default. This is done with a panel regression. The CDS premium $\left(S_{i t}\right)$ is related to the firm's own equity volatility $\left(\sigma_{E, P, d_{i t}}\right)$, the market-wide equity volatility $\left(\sigma_{S \& P, P, d_{t}}\right)$, the risk-free interest rate $\left(R_{t}\right)$ and the firm's leverage $\left(L_{i t}\right)$. To calculate equity volatility and leverage we use equity data and quarterly balance sheet information obtained respectively from the Center for Research in Security Prices (CRSP) database and the COMPUSTAT database.

$$
S_{i t}=\beta \sigma_{E, P, d_{i t}}+\delta \sigma_{S \& P, P, d_{t}} \times \sigma_{E, P, d_{i t}}+\gamma R_{t}+\nu L_{i t}+\varepsilon_{i t}
$$

where subscript $i$ denotes the firm and subscript $t$ denotes the period at which the observation is made.

Dropping the $i$ and $t$ subscripts, the sensitivity of the CDS price to equity volatility from (8) is:

$$
\frac{\partial S}{\partial \sigma_{E, P, d}}=\beta\left(\frac{\partial \sigma_{E, P, d}}{\partial \sigma_{E, P, d}}\right)+\delta\left[\left(\frac{\partial \sigma_{E, P, d}}{\partial \sigma_{E, P, d}}\right) \times \sigma_{S \& P, P, d}+\left(\frac{\partial \sigma_{S \& P, P, d}}{\partial \sigma_{E, P, d}}\right) \times \sigma_{E, P, d}\right]
$$

\footnotetext{
${ }^{20}$ These monthly data relate to the UK stock index each month over 2002 to 2006 . The estimated ratio is 2.18 . The maturity matching operated in the MSKEW calibration further differentiates our methodology from Zhang, Zhou, and Zhu (2009) and Cremers, Driessen, and Maenhout (2008). We thank the referee for highlighting this point.
} 
Over the in-sample period the $\mathrm{S} \& \mathrm{P}$ volatility is 0.619 times as large as the volatility of the average firm. Because firm volatility and $\mathrm{S} \& \mathrm{P}$ volatility cannot drift apart in the long run (i.e. are cointegrated), expected changes in the two variables can be written as $\frac{\partial \sigma_{S \& P, P, d}}{\partial \sigma_{E, P, d}}=0.619$. The first derivative in (9) can then be written more simply as:

$$
\frac{\partial S}{\partial \sigma_{E, P, d}}=\beta+\delta\left(\sigma_{S \& P, P, d}+0.619 \sigma_{E, P, d}\right)
$$

Combining equations (5), (6), and (9') we obtain:

$$
\begin{aligned}
\frac{\partial S}{\partial \sigma_{E, Q, 5}} & =2\left(\frac{\partial S}{\partial \sigma_{E, P, d}}\right) \\
& =2\left(\beta+\delta \sigma_{S \& P, P, d}+0.691 \delta \sigma_{E, P, d}\right)
\end{aligned}
$$

The nice feature of equation (10), and of the specification of equation (8) from which it is derived, is that the sensitivity of a firm's CDS price to changes in its equity volatility $\left(\frac{\partial S}{\partial \sigma_{E, Q, 5}}\right)$ is not constant, but varies over time both with the volatility of the S\&P index and with the firm's own equity volatility. ${ }^{21}$

The coefficients $\beta$ and $\delta$ are estimated with the panel regression of equation (8), using the 193 weeks of data prior to the Lehman default. Because the aim is to explain both time-series and cross-section effects, we exclude a constant, any fixed effects and other control variables. As shown in Table 3, all of the variables are significant at the $1 \%$ level (according to the t-statistics); the estimated value for $\beta$ is 0.791 and for $\delta$ is 0.058 . The $\mathrm{R}$-squared is 0.355 .

As a check on this calibration we have also searched over the pre-Lehman period, with the MSKEW specification and Merton's model, for the $\beta$ and $\delta$ coefficients that minimize mean-squared errors. This procedure yields exactly the same coefficients for $\beta$ and $\delta$ as found with the panel regression.

The next two Figures, 6 and 7, show the smiles from the calibrated MSKEW model for $19^{\text {th }}$ March 2006 and $21^{\text {st }}$ September 2008 (the same two dates as already illustrated for the MEIV calibration in Figures 4 and 5). On the first, in-sample date, the fit to the observed CDS smile is remarkably close and it remains so throughout the period before the Lehman default. On the second, just out-

\footnotetext{
${ }^{21} \overline{\text { Note that we do not allow } \frac{\partial S}{\partial \sigma_{E, P, d}} \text { to depend }}$ on leverage, $L$. We make this judgement on specification from the insights of the Merton model, as explained in Appendix C.
} 
of-sample date, the forecast smile is above the observed smile because equity volatilities have risen but CDS prices have not yet done so.

\section{Time-Series and Cross-Section Forecasts from the Calibrations}

In this section of the paper we examine how well forecasts from the two calibrations of the Merton model, made with parameters estimated from the pre-Crisis period, perform during and after the Crisis.

\subsection{Time-Series Performance}

Figure 8 compares weekly-average market and model CDS prices across the 40 firms over the whole 2005-2012 period (both before and after the Lehman default). In the two months after the default of September 2008, both MEIV and MSKEW forecasts track the huge run-up in prices quite well. In fact they tend to overshoot, so we may conclude that market prices were not excessively high at the peak of the Crisis. The tracking of the two calibrations remains good during 2009. Thereafter the MEIV forecasts fluctuate rather widely around the average market level, while the MSKEW forecasts are more stable but are below the market level most of the time.

Table 4 compares the implied asset volatilities, prices and forecast errors from the MEIV and MSKEW calibrations more formally. It also gives information on the prices resulting from a traditional implementation of the Merton model. ${ }^{22}$ The table is divided into pre-Crisis, in-Crisis and post-Crisis periods.

We note that in each sub-period the (Q-measure) asset volatilities from the MEIV and MSKEW calibrations in Table 4 are larger than the implied asset volatilities from the traditional model and also larger than the observed P-measure equity volatilities given in Table 1. For a firm with no debt, the P-measure asset volatility would also equal the P-measure equity volatility and so the latter can be seen as an upper bound to that asset volatility. ${ }^{23}$

${ }^{22}$ In an earlier version of the paper, we implemented the Schaefer and Strebulaev (2008) adjustment to Merton's traditional model, in which more leverage contributes to a higher asset volatility. While this adjustment is convincing, it contributes only a very small increase to CDS prices in our sample, even for firms with the highest leverage. We therefore do not report those results here.

${ }^{23} \mathrm{~A}$ full understanding of the pricing of CDS contracts would require a full understanding of the preferences that generate the gap between the Q-measure and P-measure asset probabilities. In this paper - however - we do not seek to write a preferences-based model for the pricing of CDSs, instead we study whether CDS pricing is consistent across periods given those preferences. 
The first numeric column of Table 4 gives values for the 193 pre-Crisis weeks. As this was the period used for initial calibration, it can tell us little about the performance of the different approaches except that the traditional model can be rejected: it gives a mean price of 2 basis points and a median of 0 basis points, whereas the market price has a mean of 40 basis points and a median of 32 basis points in this period. One of the reasons that it gives this low value for the price is that it uses an average asset volatility of $20 \%$ when the implied value is $43 \%$ (as shown at the top left of the table).

The most important results are in the second and third numeric columns, giving results for the 68 inCrisis weeks immediately following the Lehman default and the 157 post-Crisis weeks from January 2010 to December 2012. Both of these periods are out-of-sample. During the in-Crisis period, the market price averages 124 basis points and the two calibrations give averages of 131 (MSKEW) and 113 (MEIV) basis points. The calibrated average prices are therefore close to the market average over this period, as are the calibrated asset volatilities (both being $50 \%$, versus $49 \%$ for the market), but the median prices tell a slightly different story. While the market median price is 74 basis points, the medians for the two calibrations are higher, being 120 (MSKEW) and 109 (MEIV) basis points. For a typical (median) firm, the two calibrations therefore overshoot in terms of prices during the in-Crisis period.

During the post-Crisis period (third numeric column of the table), the mean price in the market is 94 basis points and the MEIV mean price is the same but the MSKEW mean price is much lower, at 52 basis points. That is a result to which Figure 8 has already drawn attention: the MSKEW calibration leads to average post-Crisis forecasts over 2010-2012 that are below those of the MEIV calibration, with the latter being close to the market average. If the medians are compared for the post-Crisis period, the market average is 71 basis points, the MEIV value is rather higher at 92 basis points and the MSKEW value is rather lower at 48 basis points.

So far in discussing the forecasts in Table 4 we have examined representative values, the means and medians. At the bottom of the table the mean-squared pricing errors and the root mean-squared pricing errors are given. Interestingly, there is little difference in mean-squared forecasting errors between the two calibrations, either for the in-Crisis period or for the post-Crisis period. For example, during the in-Crisis period the mean-squared error for the MSKEW calibration is 13530 basis points and for the MEIV calibration is 14694 basis points. For the post-Crisis period the ranking is reversed, 
with a higher MSKEW value (5903 basis points) than MEIV value (5421 basis points). It follows that, although the mean and median prices from the MSKEW calibration show more bias than those from the MEIV calibration, the underpricing being $-45 \%$ on average in the post-Crisis period (as shown in the two-from-bottom segment of the table), the MSKEW prices are also more stable and that leads to mean-squared errors that are similar for the two calibrations. At this stage we cannot say that one calibration is better than the other. The reason for the contrast in mean (median) and mean-squared error performance is addressed in the next sub-section.

\subsection{Cross-Section Performance (Volatility Smiles)}

Another way to examine the calibrations is to compare their cross-sections of forecast volatilities, i.e. their volatility smiles. This is done in Figure 9 for three separate weeks in the post-Crisis period of 2010-2012. The forecast smiles for the two different calibrations have a similar shape, but the smile for the MEIV is consistently above that for the MSKEW, as would be expected from the results on prices in Table 4.

A closer examination of the smiles (curves) in Figure 9 shows that the MSKEW smile maps-out a lower bound for the market volatilities (the diamond-shaped dots) in these weeks. And it also does this for most other weeks in the post-Crisis period that we have examined (not shown here). There is a good reason for the forecasts to trace such a bound. Before the Crisis, as can be seen for some particular weeks by looking back to Figure 2, all firms lie closely along the market smile. Given a particular leverage level, there is almost no variation across firms in implied volatility, so there is almost no idiosyncratic risk that affects CDS prices. The average R-squared value for the fitted smiles across the 193 pre-Crisis weeks is 0.80 , i.e. only $20 \%$ of the variance is idiosyncratic. In the Post-Crisis period from 2010 to 2012 (as also shown for some particular days in Figure 2), firms show much more idiosyncratic risk: for the 157 post-Crisis weeks the fitted curves have an average $\mathrm{R}$-squared of 0.54 , implying that $46 \%$ of the variance is now idiosyncratic. Idiosyncratic risk (apart from own equity volatility) is not an input to our calibrations of Merton's model and, if present, will raise CDS prices and implied volatilities. It cannot lower them. Hence the tracking of a lower bound to the smile by the MSKEW calibration, reflecting the absence of idiosyncratic risk for some firms but its substantial presence for others, is entirely to be expected.

Another way of seeing this is by inverting the market-implied volatilities defined by a curve fitted 
to the bound and then estimating the corresponding market-implied risk-neutral distributions (at the bound) over different weeks. Figure 10 plots the implied tails of these estimated risk-neutral distributions over the period 2006-2012, focusing on one week in each of the years 2006, 2008, 2010 and 2012. The fattest tail, not surprisingly, is in December 2008, revealing a higher systematic risk priced in CDSs. By March 2010 the tail has become intermediate in size and by March 2012 the tail has diminished to be almost exactly the same size as it had been six years earlier, in March 2006 .

Taken together, the evidence from Figures 9 and 10 indicates that the MSKEW works well in the post-Crisis period for firms which are near-to the lower bound, i.e. for those firms which have very little firm-specific risk. After the Crisis something has changed: there is an increase in idiosyncratic risk priced in some of these investment-grade CDS contracts, which is precisely what the MSKEW forecasts suggest.

\subsection{What are these extra Post-Crisis Idiosyncratic Risks?}

Having concluded that idiosyncratic risks rise after the Crisis, we would like to know what the new risks are. We hypothesise that liquidity, uncertainty about a firm's performance and ratings may be relevant and we use them in panel regressions to explain forecast errors. With respect to liquidity, we use two measures. The first is firm size and we take its inverse to adjust for the long right-hand tail of this variable. The second measure of liquidity is the bid/ask spreads on a firm's CDS contracts. Because the bid/ask rises directly with the CDS price, we take only that part of it which is orthogonal to the CDS price. With respect to uncertainty about a firm's performance, this is measured by the range of forecasts of earnings per share for a firm, as suggested by Buraschi, Trojani and Vedolin (2014). With respect to ratings, they are included because they may reflect information that is relevant but does not yet affect a firm's equity volatility. We use S\&P ratings and scale them (as before) from 1 for AAA to 16 for B-, so a higher score indicates a lower rating.

We use forecast errors from the MSKEW and MEIV calibrations as the dependent variables in panel regressions and the results are shown in Table 5. For the MSKEW calibration the $R^{2}$ is 0.44 and for the MEIV it is 0.47 . In both cases the only variable that is of low significance and has the wrong sign is that for CDS bid/ask. The other three variables - firm size, uncertainty of earnings, and ratings - all have positive coefficients and are significant (using heteroscedasticity-corrected standard errors and covariances) at the $0.1 \%$ level. The estimated impacts of one-standard-deviation 
changes in variables are very similar across the two different calibrations: the contributions of firm size, earnings uncertainty, and rating are 20,23 and 19 basis points respectively for the MSKEW calibration and 22, 29, and 21 basis points respectively for the MEIV calibration. Note, however, that the constant in the regression is significantly negative for the MEIV errors (-74 basis points) but it is not significantly different from zero for the MSKEW errors. This is another indication that the higher average prices from MEIV forecasts may be rather misleading. To summarise, the regressions confirm that both calibrations omit idiosyncratic factors (relating to liquidity, uncertainty and ratings) that have a large positive impact on CDS prices in the post-Crisis period of 2010-2012.

Our results on the role of idiosyncratic risks may be compared with those in Coro, Dufour and Varotto (2013). Using panel regressions, they conclude that liquidity risk rather than credit risk was the dominant factor for CDS prices both before and during the Crisis. A similar conclusion on the role of liquidity risk is reached by Meine, Supper and Weiss (2015). By contrast, we conclude that (systematic) credit risk was the only important factor in the pre-Crisis period, but that liquidity and other idiosyncratic factors mattered for some (but not all) firms in the post-Crisis period.

\section{Conclusions}

The aim of this paper was to examine whether Merton's model could explain CDS prices in the context of the Credit Crisis. Our first conclusion is that using the model allowed us to reveal clear volatility smiles in CDS prices, when individual firms' implied volatilities were plotted against leverages. Before the Crisis these smiles were particularly well-defined, indicating that all firms of a given leverage were treated by investors as being the same - there was almost no role for firm-specific (idiosyncratic) risk at that time. After the Lehman default, the smiles were still easy to discern, but their shapes changed more frequently from week to week. There was also considerable variation of implied volatilities above and below the estimated curves, so idiosyncratic risks now affected CDS prices much more than before.

In order to examine what was underlying the changing shapes of the smiles (and hence of the riskneutral distributions of firm value), we developed two different calibrations of Merton's model. These were estimated with pre-Crisis data and then used to make forecasts during and after the Crisis. One of the calibrations (the MSKEW) was based on historic relationships between CDS smiles and observed volatilities. The other calibration (the MEIV) was based on relating the shape of the CDS 
smile to the concurrent shape of the equity-index-option smile. The two calibrations were able to forecast a large proportion of the cross-section variation of CDS prices and also much of their timeseries variation. By contrast, a traditional calibration of the model generated prices that were close to zero, except in the period immediately after the Lehman default when equity volatility was at its peak. Our second conclusion is therefore that Merton's model can be useful for understanding what determines CDS prices, but it needs to be calibrated to the skewed risk-neutral distribution rather than to the observed equity volatility.

In the introduction to this paper, we posed three empirical questions. The first was whether the increase in CDS prices soon after the Lehman default could be justified, to which the answer is "yes". The prices predicted for that time by both of our calibrations were even higher than those observed in the market.

The second question was why average prices remained at least twice as high in 2010-2012, long after the Crisis, as they had been prior to the Crisis in 2005-2007. The answer is that before the Crisis there was almost no role for idiosyncratic risk in determining CDS prices, but afterwards such risk became permanently important for about half of the firms in our sample. From analysing forecast errors after the Crisis, we found that the newly important specific risks that affected CDS prices were threefold: a firm's liquidity, the uncertainty of its earnings and its current rating.

The third question was why the mean CDS price was much higher than the median after the Crisis, when it was not higher before. The answer is that the median firm was not greatly affected by idiosyncratic risk after the Crisis, but the mean was increased by the impact of that risk on a large subset of firms. Such extra risk could only increase CDS prices for the relevant firms (and not decrease them), because of the low level of idiosyncratic risk in the pre-Crisis period. The result was a skewed distribution of CDS prices in cross-section, resulting in the mean exceeding the median.

The Merton model is simple and the calibrations in this paper, although novel, are also relatively simple. More research on what determines the risk-neutral distribution of firm value (and hence of volatility smiles) is important, because the values of both equity and debt depend on that single distribution. The integration of asset pricing across equity and debt markets remains a potentially rich field for further research. 


\section{References}

Arora, N., J. Bohn, And F. Zhu (2005): "Reduced Form vs. Structural Models of Credit Risk: A Case Study of Three Models," Journal of Investment Management, 3(4), 43-67.

Avramov, D., G. Jostova, and A. Philipov (2007): "Understanding Changes in Corporate Credit Spreads," Financial Analysts Journal, 63(2), 90-105.

BAI, J., And L. Wu (2016): "Anchoring Credit Default Swap Spreads to Firm Fundamentals," Journal of Financial and Quantitative Analysis, 51(5), 1521-1543.

Bakshi, G., C. CaO, and Z. Chen (2000): "Pricing and Hedging Long-Term Options," Journal of Econometrics, 94(1-2), 277-318.

BAO, J. (2009): "Structural Models of Default and the Cross Section of Corporate Bond Yield Spreads," Working Paper, MIT.

BaO, J., And J. Pan (2013): "Bond Illiquidity and Excess Volatility," Review of Financial Studies, 26(12), 3068-3103.

Benkert, C. (2004): "Explaining Credit Default Swap Premia," Journal of Future Markets, 24(1), $71-92$.

Bharath, S. T., and T. Shumway (2008): "Forecasting Default with the Merton Distance to Default Model," Review of Financial Studies, 21(3), 1339-1369.

Black, F., and M. Scholes (1973): "The Pricing of Options and Corporate Liabilities," Journal of Political Economy, 81(3), 637-654.

Bollen, P. B., And R. E. Whaley (2004): "Does Net Buying Pressure Affect the Shape of Implied Volatility Functions?," Journal of Finance, 59(2), 711-753.

Broadie, M., M. Chernov, and M. Johannes (2009): "Understanding Index Option Returns," Review of Financial Studies, 22(11), 4493-4529.

Buraschi, A., F. Trojani, and A. Vedolin (2013): "Economic Uncertainty, Disagreement, and Credit Markets," Management Science, 60(5), 1281 - 1296. 
Campbell, J. Y., and G. B. Taksler (2003): "Equity Volatility and Corporate Bond Yields," Journal of Finance, 58(6), 2321-2350.

CaO, C., F. Yu, and Z. Zhong (2010): "The Information Content of Implied Volatility for Credit Default Swap Valuation," Journal of Financial Markets, 13(3), 321-434.

Carr, P., and L. Wu (2009): "Stock Options and Credit Default Swaps: A Joint Framework for Valuation and Estimation," Journal of Financial Econometrics, 8(4), 409-449.

Chen, L., D. A. Lesmond, and J. Wei (2007): "Corporate Yields Spreads and Bond Liquidity," Journal of Finance, 62(1), 119-149.

Chen, N., and S. G. Kou (2009): "Credit Spreads, Optimal Capital Structure and Implied Volatility with Endogenous Default and Jump Risk," Mathematical Finance, 19(3), 343-378.

Chen, R., N. Chidambaran, M. Imerman, and B. Sopranzetti (2014): "Liquidity, Leverage and Lehman: A Structural Analysis of Financial Institutions in Crisis," Journal of Banking and Finance, 45, 117-139.

Christoffersen, P., J. Ericsson, K. Jacobs, and X. Jin (2009): "Exploring Dynamic Default Dependence," Working Paper, McGill University.

Christoffersen, P., K. Jacobs, and C. Ornthanalai (2013): "GARCH Option Valuation: Theory and Evidence," Journal of Derivatives, 21(2), 8-41.

Collin-Dufresne, P., And R. S. Goldstein (2001): "Do Credit Spreads Reflect Stationary Leverage Ratios?," Journal of Finance, 56(5), 1929-1957.

Collin-Dufresne, P., R. S. Goldstein, and J. Helwege (2010): "Is Credit Event Risk Priced? Modeling Contagion via the Updating of Beliefs," NBER Working Paper No. 15733.

Collin-Dufresne, P., R. S. Goldstein, and F. Yang (2012): "On the Relative Pricing of Long Maturity Index Options and CDX Tranches," Journal of Finance, 67(6), 1983-2014.

Coro, F., A. Dufour, and S. Varotto (2013): "Credit and Liquidity Components of Corporate CDS Spreads," Journal of Banking and Finance, 37(12), 5511-5525. 
Coval, J. D., J. Jurek, and E. Stafford (2009): "Economic Catastrophe Bonds," American Economic Review, 99(3), 628-66.

Cremers, M., J. Driessen, and P. Maenhout (2008): "Explaining the Level of Credit Spreads: Option-Implied Jump Risk Premia in a Firm Value Model," Review of Financial Studies, 21(5), 2209-2242.

Cremers, M., J. Driessen, P. Maenhout, and D. Weinbaum (2008): "Individual Stock-Option Prices and Credit Spread," Journal of Banking and Finance, 32(12), 2706-2715.

Crosbie, P., And J. Bohn (2003): "Modelling Default Risk-Modelling Methodology," Moody's KMV Paper.

Culp, C., Y. Nozawa, and P. Veronesi (2018): "Option-Based Credit Spreads," American Economic Review, 108(2), $454-488$.

Delianedis, G., and R. Geske (2001): "The Components of Corporate Credit Spreads: Default, Recovery, Tax, Jumps, Liquidity and Market Factors," UCLA Working Paper.

Derman, E., I. Kani, And J. Z. Zou (1996): "The Local Volatility Surface: Unlocking the Information in Index Options Prices," Financial Analysts Journal, July-August, 25-36.

Dick-Nielsen, J., P. Feldhütter, and D. Lando (2012): "Corporate Bond Liquidity before and after the Onset of the Subprime Crisis," Journal of Financial Economics, 103(3), 471-492.

Doshi, H., J. Ericsson, K. Jacobs, and S. M. Turnbull (2013): "Pricing Credit Default Swaps with Observable Covariates," Review of Financial Studies, 26(8), 2049-2094.

Du, D., R. Elkamhi, and J. Ericsson (2019): "Time-Varying Asset Volatility and the CreditSpread Puzzle," Journal of Finance, Forthcoming.

Elton, E. J., M. J. Gruber, D. Agrawal, and C. Mann (2001): "Explaining the Rate Spread on Corporate Bonds," Journal of Finance, 56(1), 247-277.

Engle, R., and E. Siriwardane (2014): "Structural GARCH: The Volatility-Leverage Connection," Working Paper, NYU Stern School of Business. 
Eom, Y. H., J. Helwege, and J. Huang (2004): "Structural Models of Corporate Pricing: An Empirical Analysis," Review of Financial Studies, 17(2), 499-544.

Feldhütter, P., and S. Schaefer (2018): "The Myth of the Credit Spread Puzzle," Review of Financial Studies, 31(8), 2897-2942.

Flannery, J. M., and R. K. P. (2006): "Partial Adjustment toward Target Capital Structures," Journal of Financial Economics, 79, 469-506.

Gemmill, G., and A. Keswani (2011): "Downside Risk and the Size of Credit Spreads," Journal of Banking and Finance, 35(8), 2021-2036.

Geske, R. (1979): "The Valuation of Compound Options," Journal of Financial Economics, 7(1), $63-81$.

Huang, J., And M. Huang (2012): "How Much of Corporate-Treasury Yield Spread Is Due to Credit Risk?," Review of Asset Pricing Studies, 2(2), 153-202.

Huang, J., And H. Zhou (2008): "Specification Analysis of Structural Credit Risk Models," Finance and Economics Discussion Series 2008-55, Board of Governors of the Federal Reserve System (U.S.).

Hull, J. C., I. Nelken, And A. D. White (2005): "Merton's Model, Credit Risk and Volatility Skews," Journal of Credit Risk, 1(1), 3-28.

Jones, E., S. Mason, and E. Rosenfeld (1984): "Contingent Claim Analysis of Corporate Capital Structure: An Empirical Investigation," Journal of Finance, 39, 611-627.

Jorion, P., And G. Zhang (2007): "Good and Bad Credit Contagion: Evidence from Credit Default Swaps," Journal of Financial Economics, 84(3), 860-883.

Kelly, B., G. Manzo, and D. Palhares (2016): "Credit Implied Volatility," Working Paper, University of Chicago.

Leland, H. (2009): "Structural Models and the Credit Crisis," Haas School, University of California, Berkeley (presented at the China International Conference in Finance, July 8th).

Leland, H., And K. Toft (1996): "Optimal Capital Structure, Endogenous Bankruptcy, and the Term Srtucture of Credit Spreads," Journal of Finance, 51(3), 987-1019. 
Longstaff, F. A., and E. S. Schwartz (1995): "A Simple Approach to Valuing Risky Fixed and Floating Rate Debt," Journal of Finance, 50(3), 789-819.

Mayordomo, S., J. Pena, and E. Schwartz (2014): "Are All Credit Default Swap Databases Equal?," European Financial Management, 20(4), 677-713.

Meine, C., H. Supper, and G. Weiss (2015): "Do CDS Spreads Move with Commonality in Liquidity?," Review of Derivatives Research, 18(3), 225-261.

Merton, R. (1974): "On the Pricing of Corporate Debt: The Risk Structure of Interest Rates," Journal of Finance, 29, 449-470.

Schaefer, S. M., and I. A. Strebulaev (2008): "Structural Models of Credit Risk are useful: Evidence from Hedge Ratios on Corporate Bonds," Journal of Financial Economics, 90, 1-19.

Vassalou, M., And Y. Xing (2004): "Default Risk in Equity Returns," Journal of Finance, 59(2), $831-868$.

Wang, H., H. Zhou, and Y. Zhou (2013): "Credit Default Swap Spreads and Variance Risk Premia," Journal of Banking and Finance, 37(10), 3733-3746.

Zhang, B. Y., H. Zhou, and H. Zhu (2009): "Explaining Credit Default Swap Spreads with the Equity Volatility and Jump Risks of Individual Firms," Review of Financial Studies, 22(12), 5099-5131.

Zhou, C. (2001): "The Term Structure of Credit Spreads with Jump Risk," Journal of Banking and Finance, 25, 2015-2040. 


\section{Figures and Tables}

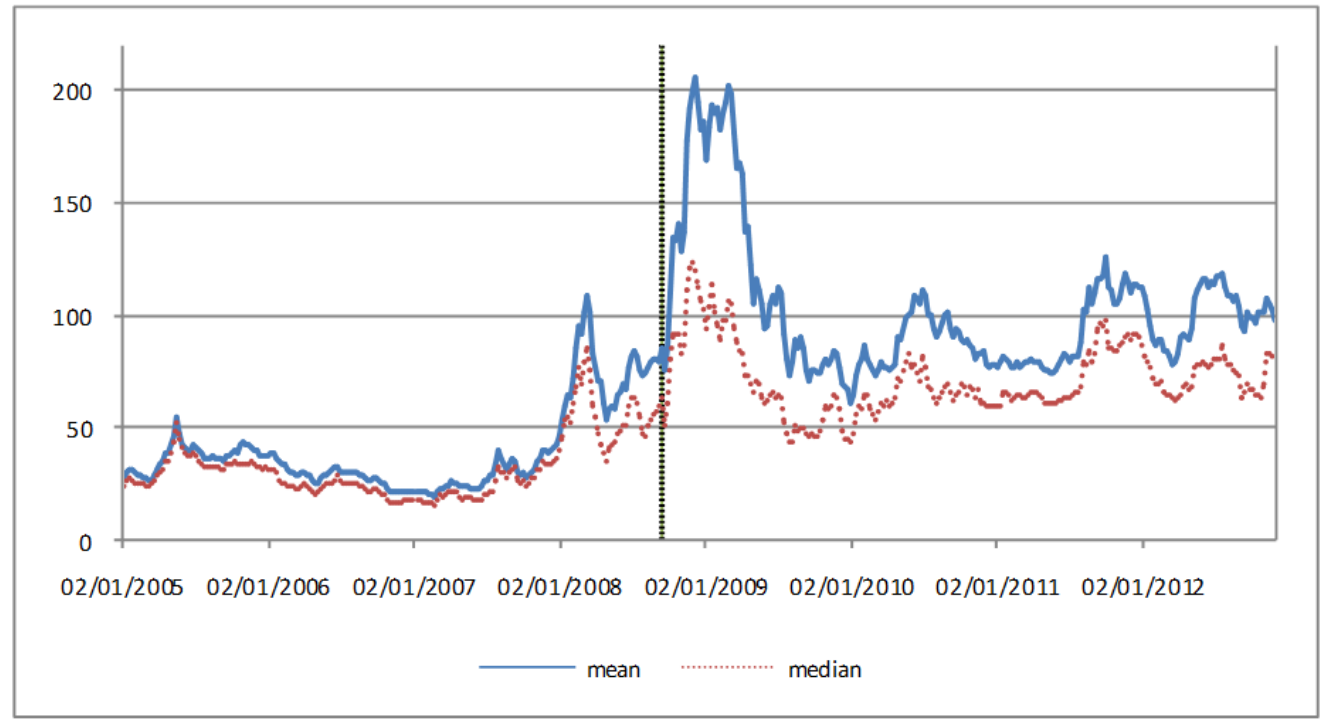

Figure 1: Mean and Median CDS Prices Over 2005 to 2012

The prices are plotted weekly for the sample of 40 firms. The data are from Markit. The vertical line indicates the week of 14 September 2008, in which the Lehman default occurred. 

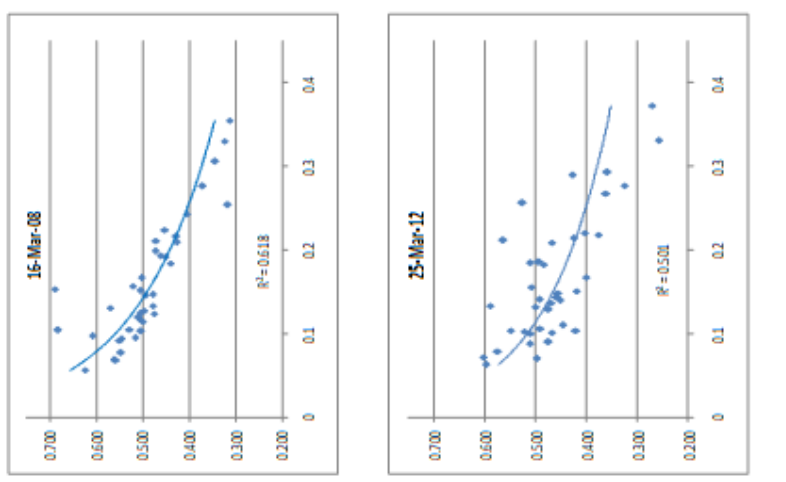

$\approx$
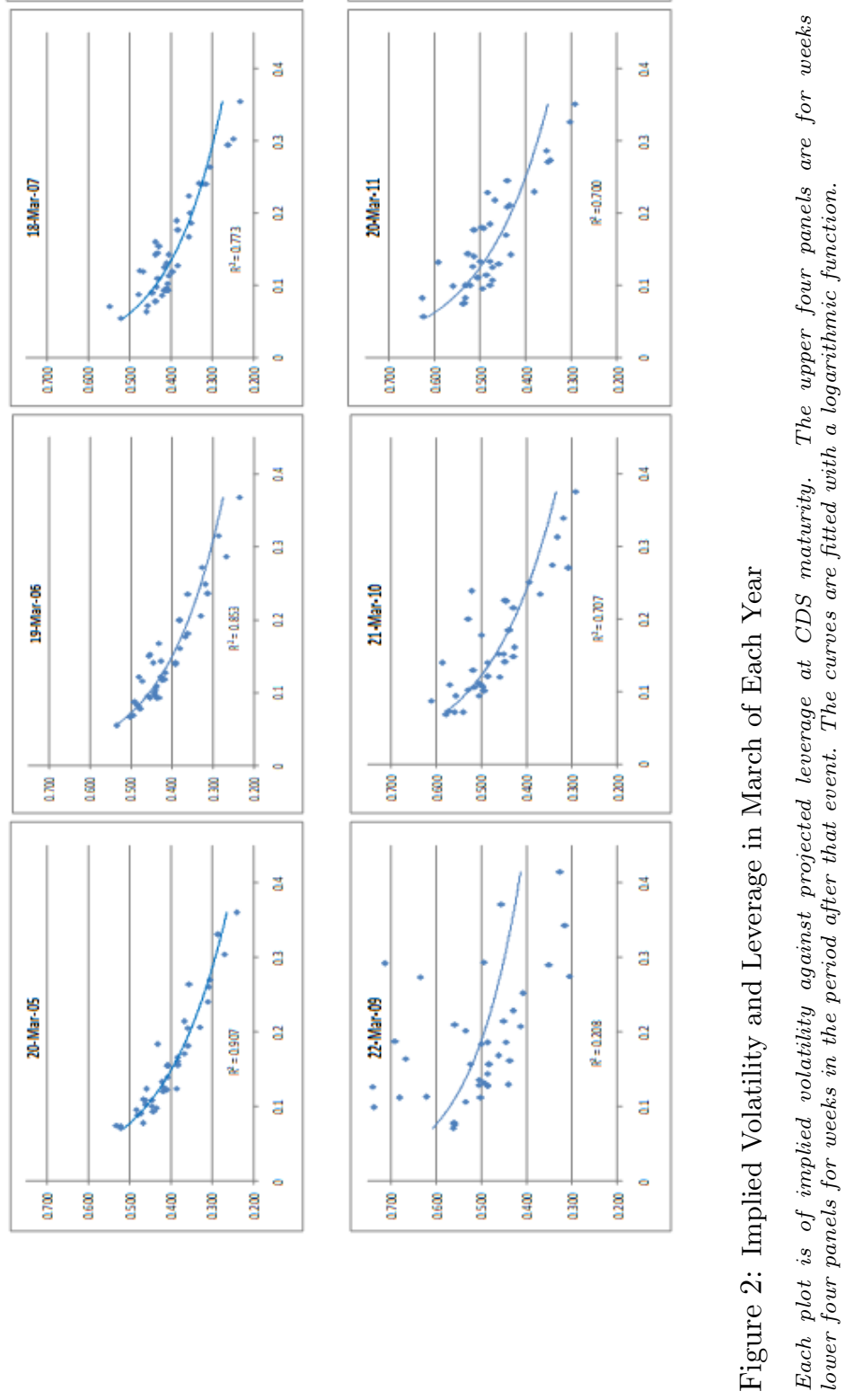


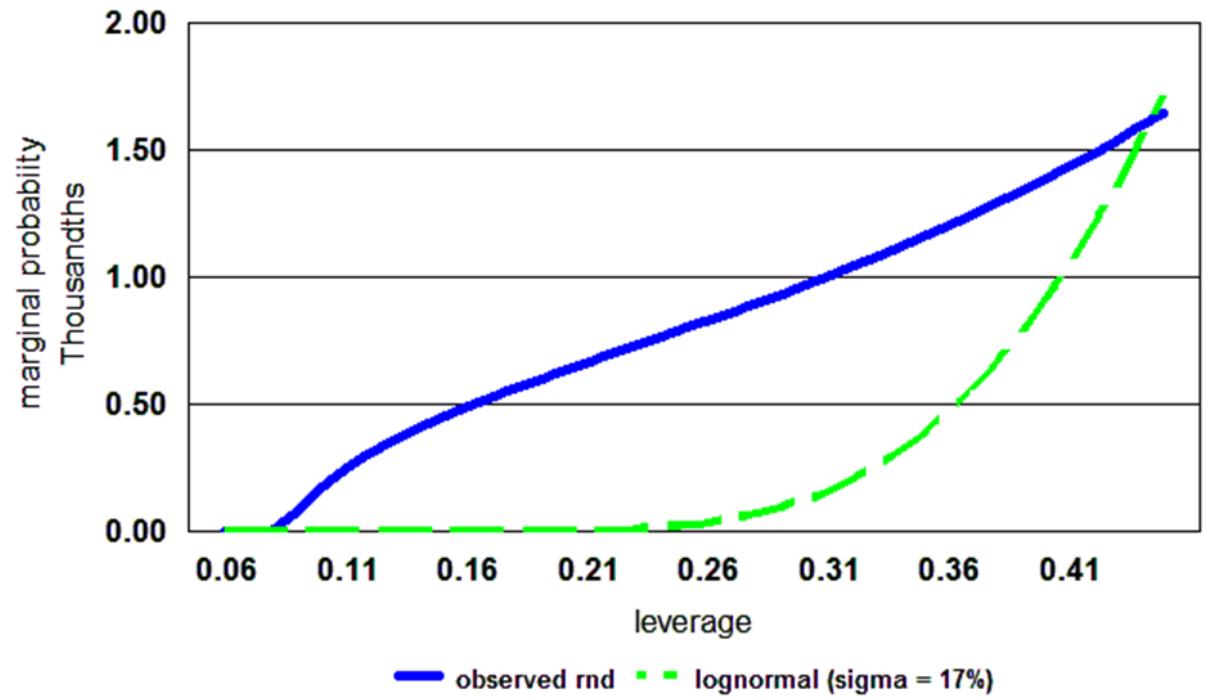

Figure 3: Left Tails of Asset-Price Distributions: Implied versus Lognormal on $19^{\text {th }}$ March 2006

The plots are probability distributions relating to 40 firms in the week of $19^{\text {th }}$ March 2006. The blue continuous line is implied from the CDS prices of the firms. The green dashed line is based on the Merton model with an asset volatility of $17 \%$. The methodology used for the implied distribution is to estimate an implied volatility for each firm with the Merton model. A logarithmic curve is then fitted to the implied volatilities against leverage, as shown in Figure 2 above. The Merton model is then inverted to give an exceeding probability at each different leverage level, from which the marginal probability distribution can be calculated. 


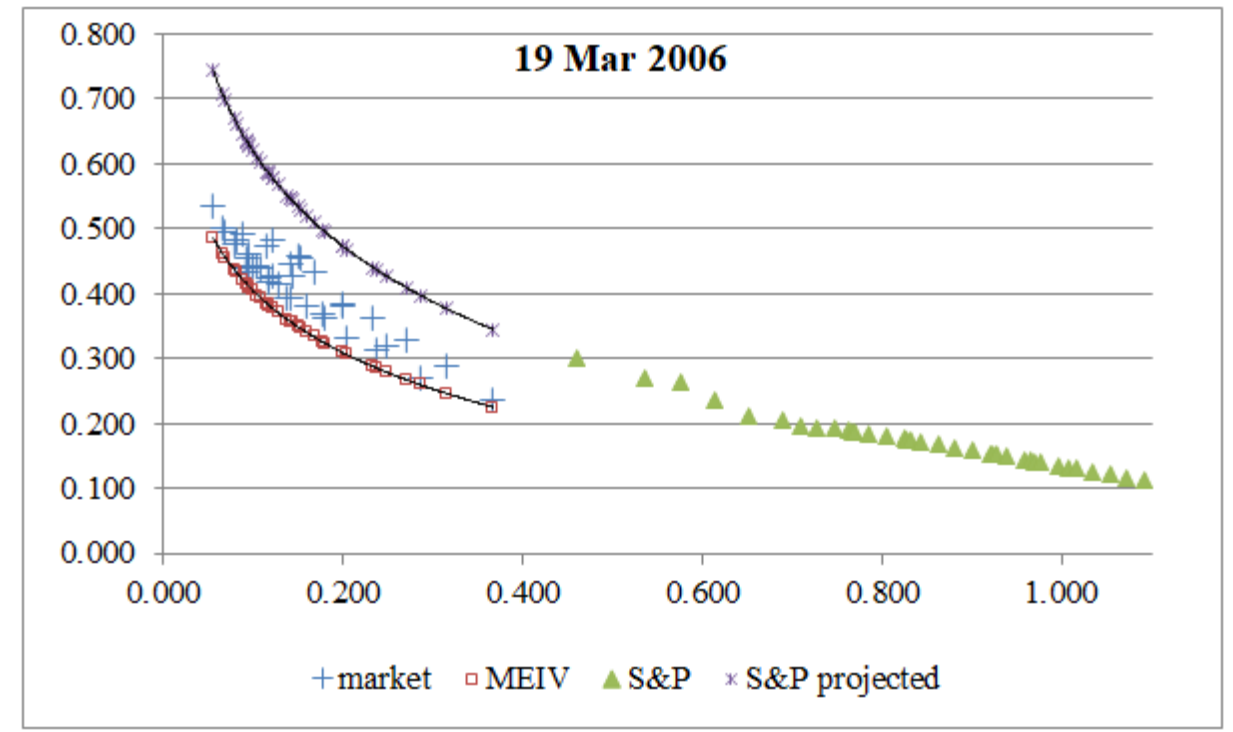

Figure 4: MEIV Calibration to Equity-Index Smile for week of $19^{\text {th }}$ March 2006

The plots are of implied volatilities against leverages for SEP index options and for CDS contracts of 40 investment-grade firms for the week of $19^{\text {th }}$ March 2006. The green triangles on the right are the implied volatilities for 9-month SEP options. The continuous line at the top left is the logarithmic projection of the 9-month SEP smile. The blue crosses on the left are the CDS-implied volatilities for individual firms. The red squares on the left are values for implied volatilities generated with the MEIV model (that is, the SESP projection adjusted by the $\theta=0.653$ factor). 


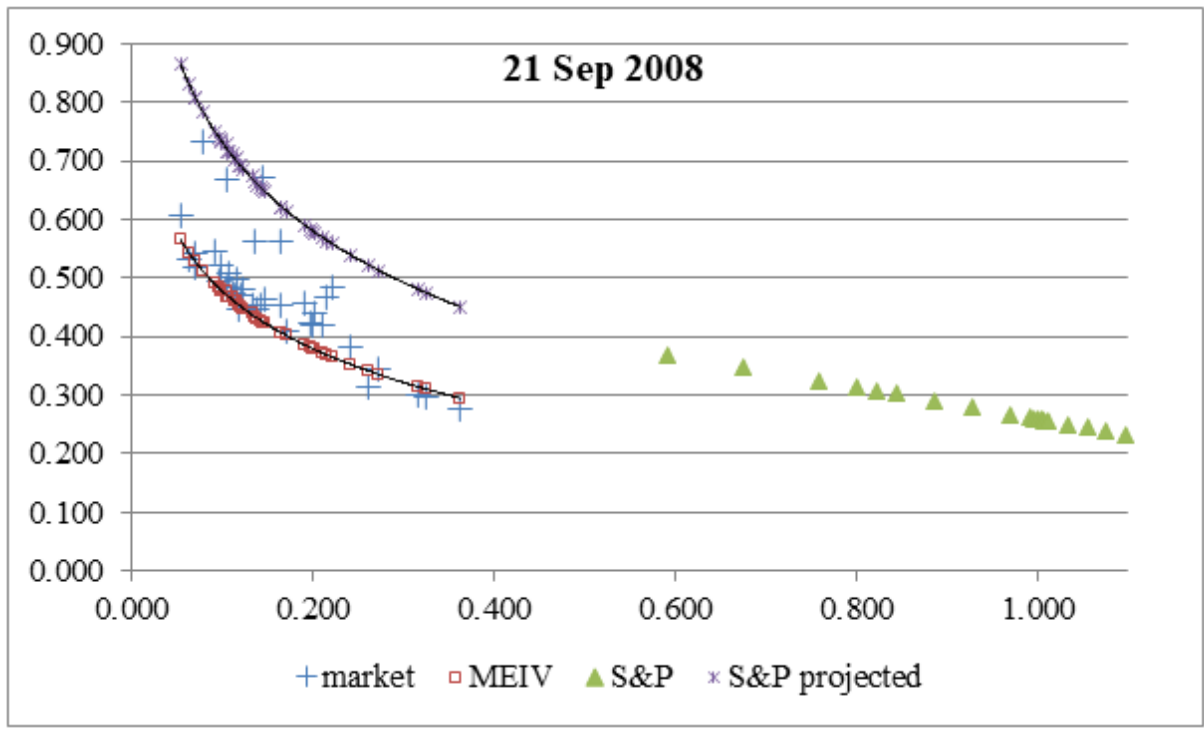

Figure 5: MEIV Calibration to Equity-Index Smile for week of $21^{\text {st }}$ September 2008

The plots are of implied volatilities against leverages for SESP index options and for CDS contracts of 40 investment-grade firms for the week of $21^{\text {st }}$ September 2008. The green triangles on the right are the implied volatilities for 9-month SEP options. The continuous line at the top left is the logarithmic projection of the 9-month SEP smile. The blue crosses on the left are the CDS-implied volatilities for individual firms. The red squares on the left are values for implied volatilities generated with the MEIV model (that is, the SEP projection adjusted by the $\theta=0.653$ factor). 


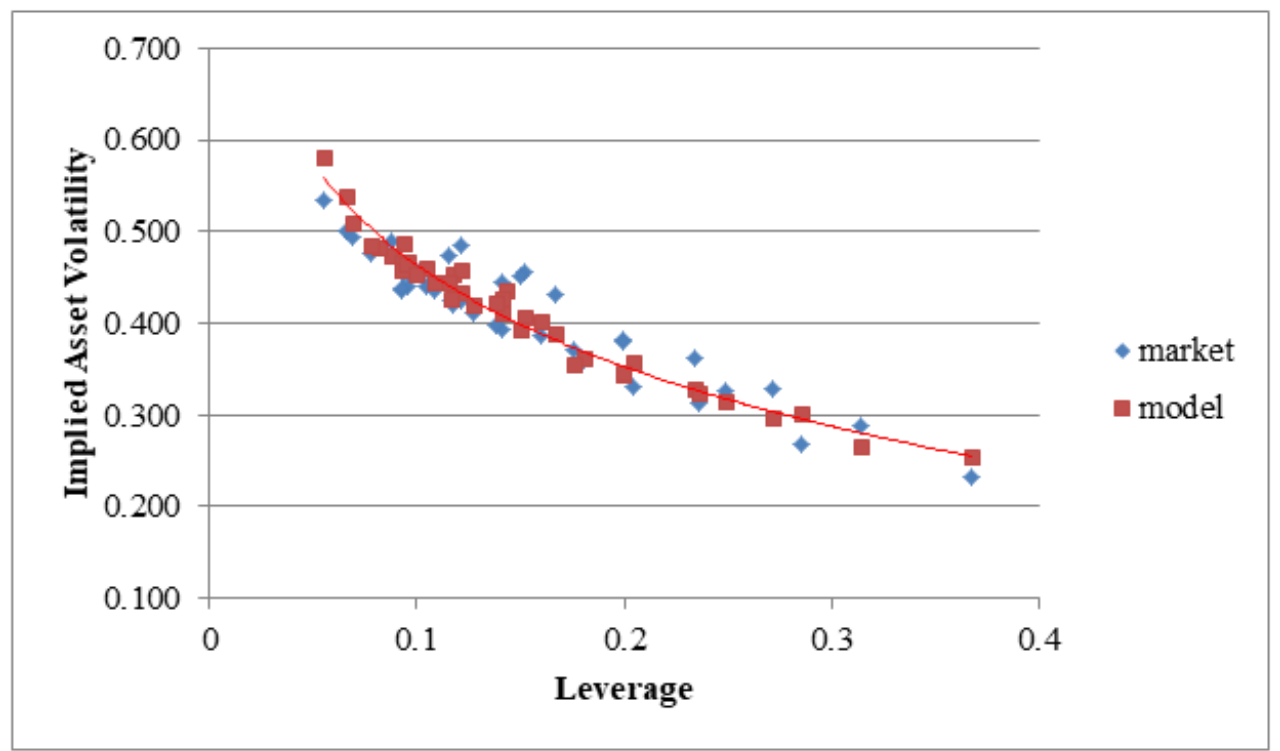

Figure 6: Implied Market Volatilities and MSKEW Volatilities for week of $19^{\text {th }}$ March 2006

The plots are of implied volatilities against leverages for CDS contracts across 40 investment-grade firms for the week of $19^{\text {th }}$ March 2006. The blue-diamond dots are values for market-implied volatilities for individual firms. The red-square dots are values generated by the MSKEW model and the line is a logarithmic fit to these observations. 


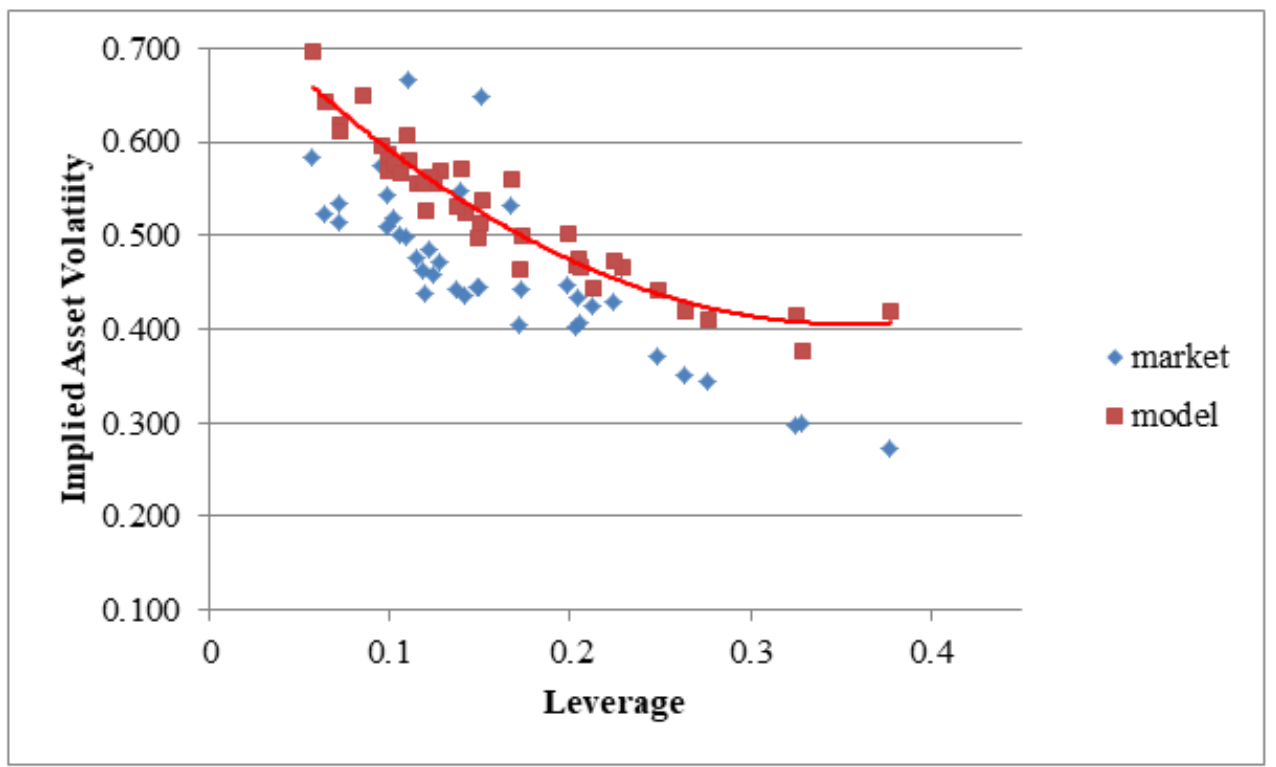

Figure 7: Implied Market Volatilities and MSKEW Volatilities for week of $21^{\text {st }}$ September 2008

The plots are of implied volatilities against leverages for CDS contracts across 40 investment-grade firms for the week of $21^{\text {st }}$ September 2008. The blue-diamond dots are values for market-implied volatilities for individual firms. The red-square dots are values generated by the MSKEW model and the line is a logarithmic fit to these observations. 


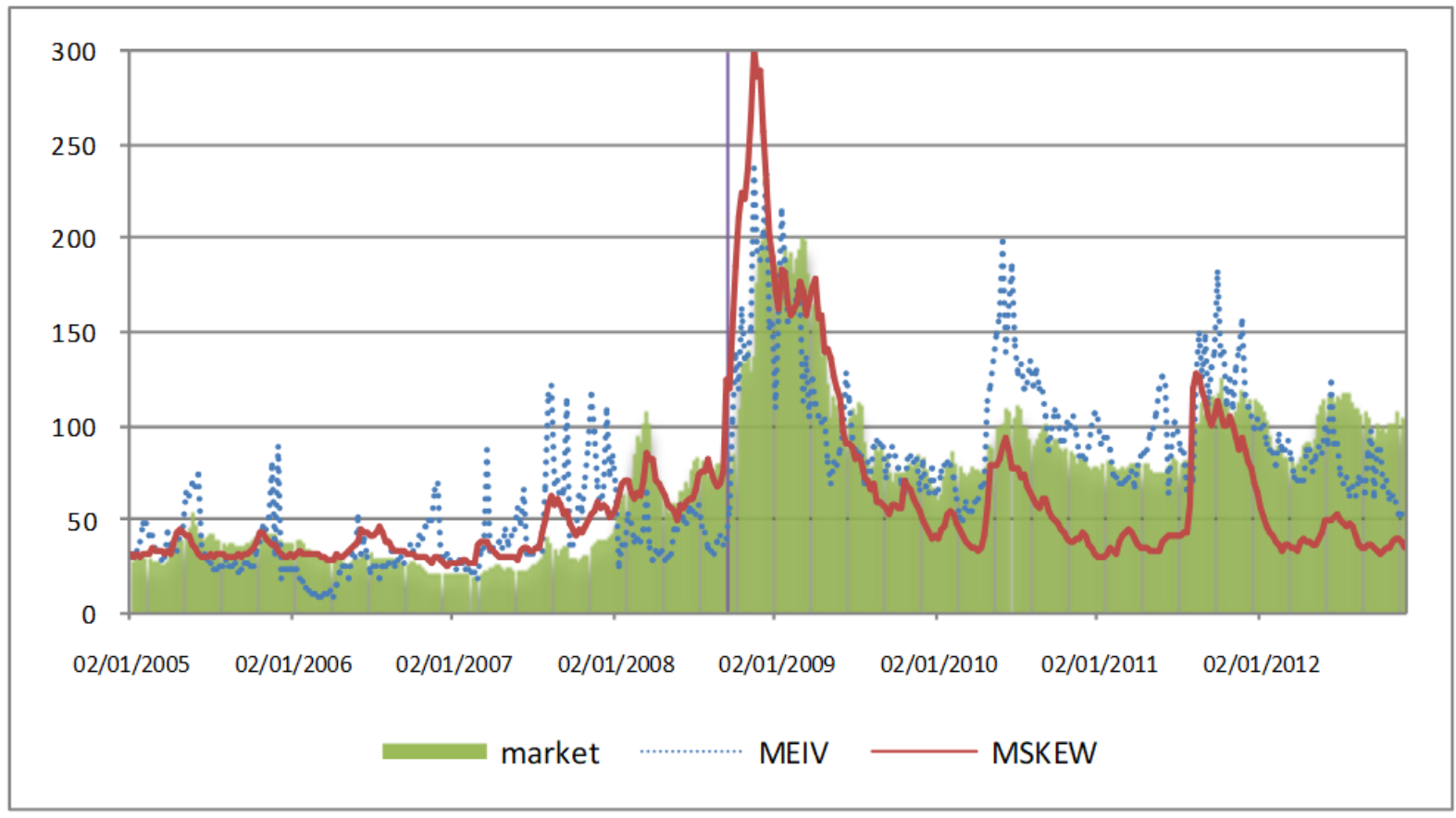

Figure 8: Calibrated and Forecasted Average CDS Prices, weekly over 2005 to 2012

The figure compares average market prices for CDS contracts across the 40 firms in a week with averages from the MEIV and MSKEW calibrations. The left-hand axis is basis points. The vertical line in the middle of the figure indicates the date of the Lehman default. The calibrated prices are in-sample up to that date and out-of-sample thereafter. 


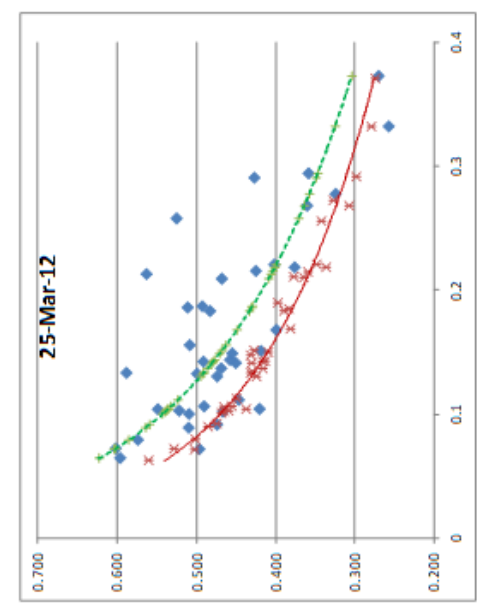

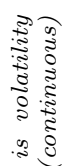

莕

है

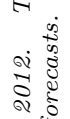

हैं

넌

จิ

娄

จे

है है

क
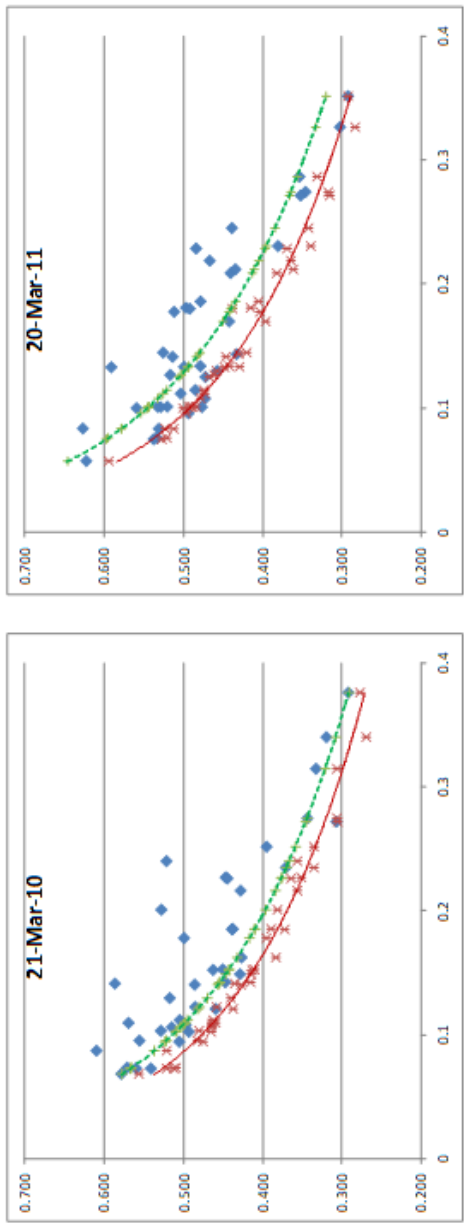

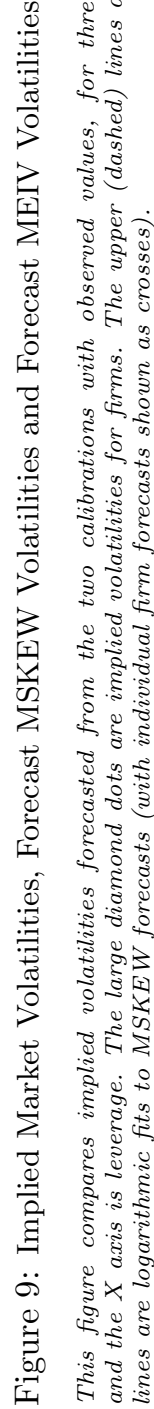




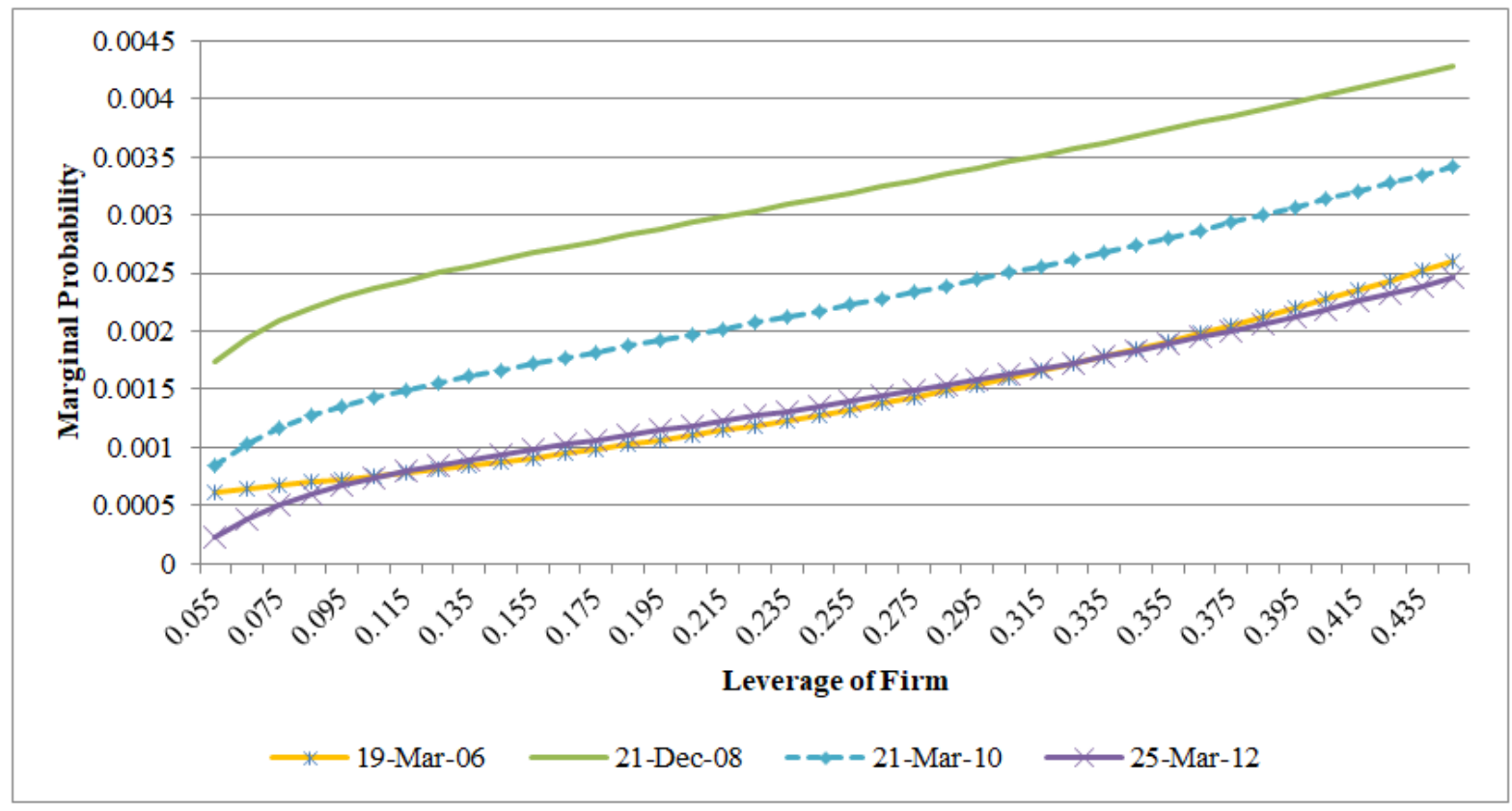

Figure 10: Implied Tails of Risk-Neutral Distributions over 2006-2012, Based on Firms at the Volatility/Leverage Bound

Each line in this figure is an implied probability distribution for firm value on the date shown. The distribution is based on implied volatilities along the lower volatility/leverage bound on that day. The methodology is the same as that described in the rubric to Figure 3. 


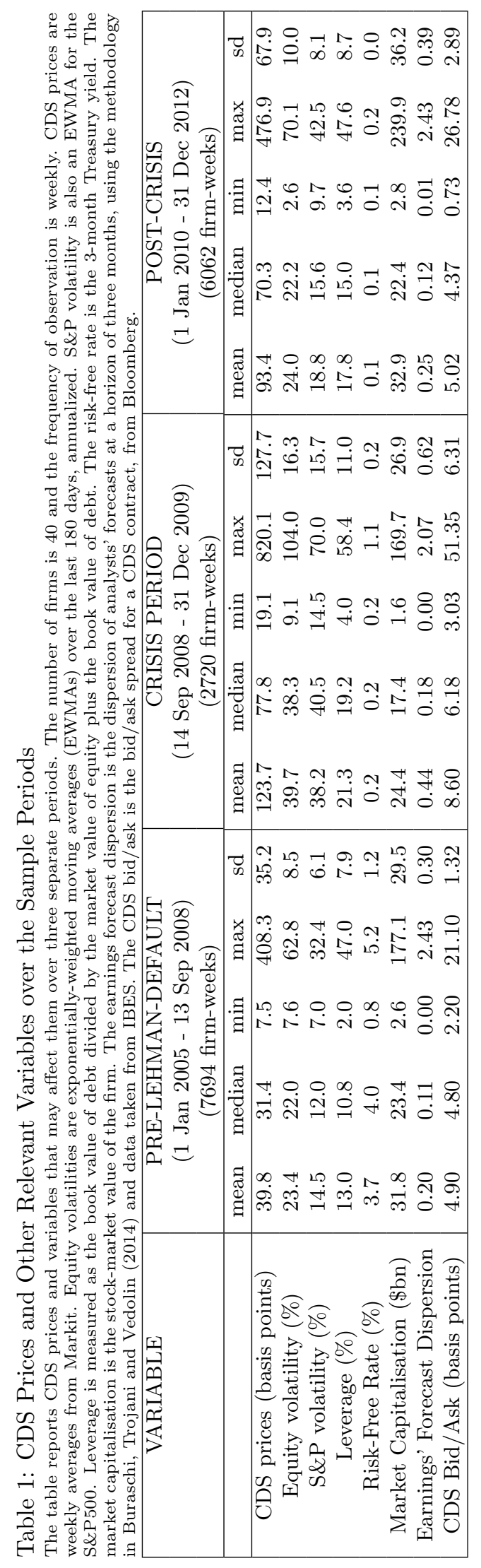


Table 2: Ratings of the Firms over the weeks of the Sample Periods The ratings are from S\&P and relate to each firm in each week. There are 40 firms.

\begin{tabular}{|c|cc|cc|cc|}
\hline RATING & \multicolumn{2}{c|}{$\begin{array}{c}\text { PRE-LEHMAN - DEFAULT } \\
\text { (1 Jan 2005 - 13 Sep 2008) }\end{array}$} & \multicolumn{2}{c|}{ CRISIS PERIOD } & \multicolumn{2}{c|}{ POST-CRISIS } \\
& number & $\%$ & number & $\%$ & 2008 & 31 Dec 2009) \\
number & $\%$ \\
\hline AA- & 39 & $0.5 \%$ & 0 & $0.0 \%$ & 35 & $0.6 \%$ \\
A+ & 290 & $3.8 \%$ & 110 & $4.0 \%$ & 122 & $2.0 \%$ \\
A & 1552 & $20.2 \%$ & 706 & $26.0 \%$ & 1653 & $27.3 \%$ \\
A- & 1692 & $22.0 \%$ & 517 & $19.0 \%$ & 891 & $14.7 \%$ \\
BBB+ & 1754 & $22.8 \%$ & 454 & $16.7 \%$ & 1093 & $18.0 \%$ \\
BBB & 1439 & $18.7 \%$ & 435 & $16.0 \%$ & 1318 & $21.7 \%$ \\
BBB- & 864 & $11.2 \%$ & 373 & $13.7 \%$ & 741 & $12.2 \%$ \\
BB+ & 64 & $0.8 \%$ & 77 & $2.8 \%$ & 157 & $2.6 \%$ \\
BB & 0 & $0.0 \%$ & 48 & $1.8 \%$ & 52 & $0.9 \%$ \\
\hline
\end{tabular}


Table 3: Panel Regression of CDS Prices on Equity Volatilities and Other Factors

The table gives the results from a panel regression of weekly cross-sections of 40 firms over the period $2^{\text {nd }}$ January 2005 to $7^{\text {th }}$ September 2008 .

The dependent variable is the CDS price for a firm in a given week.

White standard errors and covariance are used to control for heteroscedasticity. The resulting t-values are given in brackets. $*, * *$ and $* * *$ indicate significance at the $10 \%, 5 \%$ and $1 \%$ levels respectively.

\begin{tabular}{|cc|}
\hline Method & OLS \\
Fixed effects & no \\
\hline Equity Volatility & 0.791 \\
& $(6.28)^{* * *}$ \\
Equity Volatility $\times$ S\&P Volatility & 0.058 \\
& $(9.66)^{* * *}$ \\
Leverage & 38.630 \\
& $(7.07)^{* * *}$ \\
Risk-free Rate & -1.681 \\
& $(-4.19)^{* * *}$ \\
$R^{2}$ & 0.355 \\
Number of observations & 7694 \\
\hline
\end{tabular}




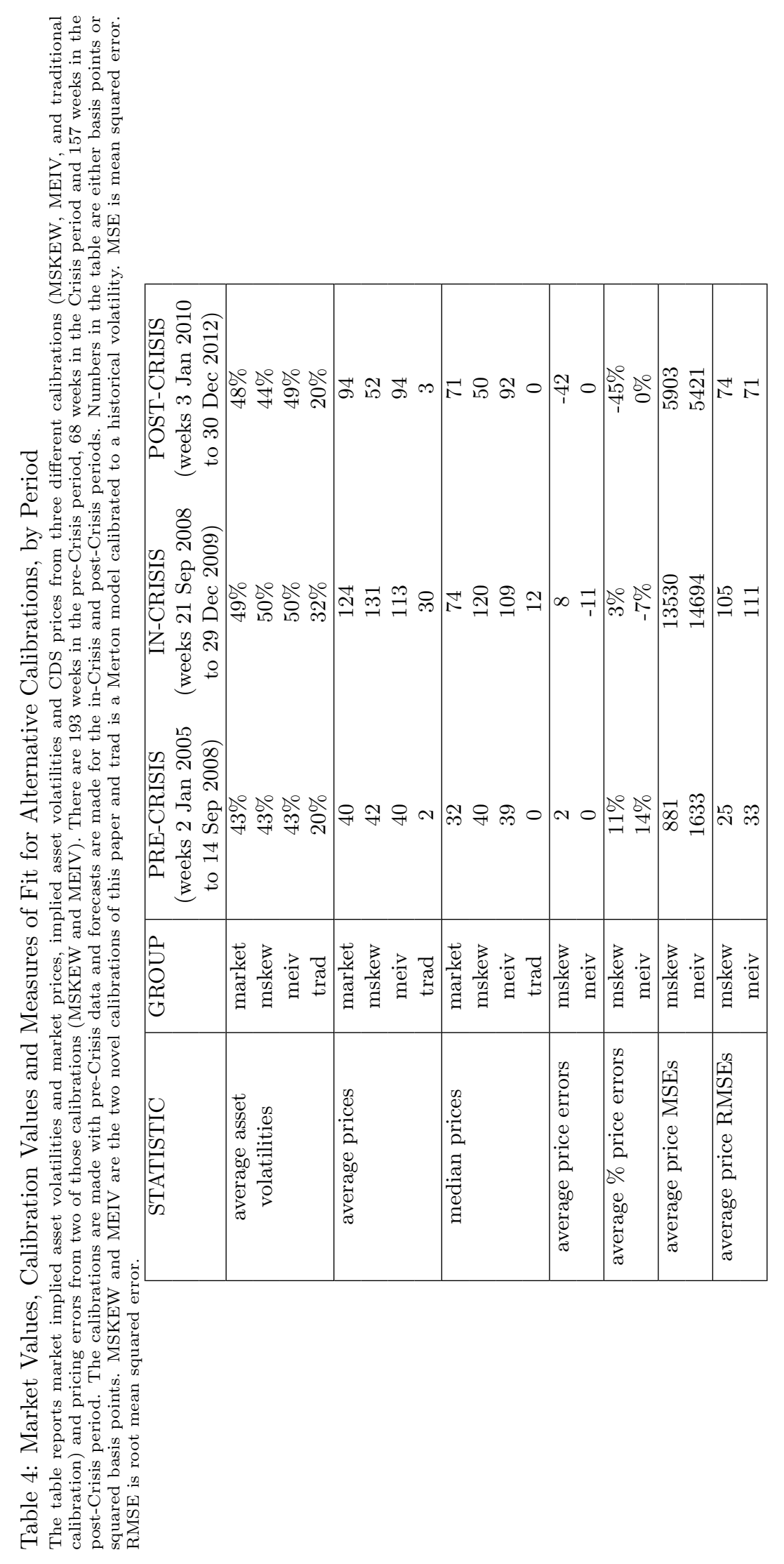




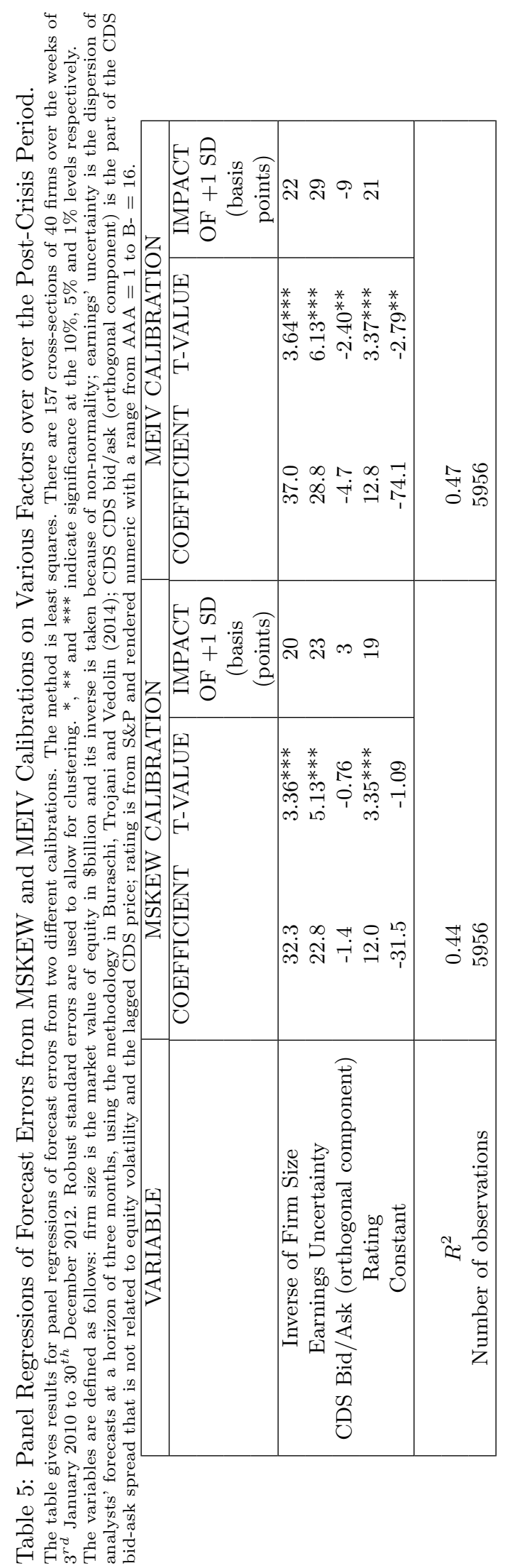




\section{Appendix A.}

\section{Merton's Model and the Sensitivity of CDS Prices to Asset Volatility}

\section{A.1. Merton's Model ${ }^{24}$}

At time 0 (today) the firm has assets $A_{0}$ and liabilities comprising bonds worth $B_{0}$ and equity worth $E_{0}$. By definition the assets equal the liabilities in value,

$$
A_{0}=B_{0}+E_{0}
$$

For simplicity, it is assumed that the firm has issued only one bond which pays no coupon. The bond matures at time $T$ and the promised payment at that time (i.e. the face value of the bond) is $D$. The equity of the firm can then be considered to be a call option on the assets with maturity $T$ and exercise price $D$. The call option pays:

$$
E_{T}=\max \left(A_{T}-D, 0\right)
$$

The market value of the firm today, $E_{0}$, depends on the distribution of the value of the assets until maturity, which is assumed to be lognormal and free of any dividend payments. Following Black and Scholes (1973) and Merton (1974) the value of the firm today is

$$
E_{0}=A_{0} N\left(d_{1}\right)-D e^{-r T} N\left(d_{2}\right)
$$

where $\mathrm{N}($.$) is the cumulative function for the standard Normal distribution,$

$d_{1}=\frac{\ln \left(\frac{A_{0} e^{r T}}{D}\right)}{\sigma_{A} \sqrt{T}}+\frac{\sigma_{A} \sqrt{T}}{2}$

and $d_{2}=d_{1}-\sigma_{A} \sqrt{T}$.

Now define leverage $L$ as the present value of the promised debt payment (discounted at the risk-free rate) relative to the value of the assets, i.e.

$$
L=\frac{D e^{-r T}}{A_{0}}
$$

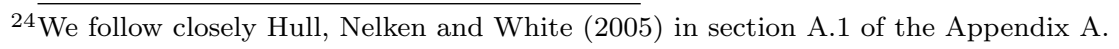


Then the value of the equity can be re-written from Equation (A.3) as,

$$
E_{0}=A_{0}\left[N\left(d_{1}\right)-L N\left(d_{2}\right)\right]
$$

and, using the definition of leverage, we can re-write $d_{1}$ more simply as:

$d_{1}=\frac{-\ln (L)}{\sigma_{A} \sqrt{T}}+\frac{\sigma_{A} \sqrt{T}}{2}$.

Because we know from Equation (A.1) that $B_{0}=A_{0}-E_{0}$, we can re-write Equation (A.5) as an expression for the value of the debt,

$$
B_{0}=A_{0}-A_{0}\left[N\left(d_{1}\right)-L N\left(d_{2}\right)\right]=A_{0}\left[N\left(-d_{1}\right)+L N\left(d_{2}\right)\right]
$$

Now define $y$ as the risky yield to maturity of the debt, such that

$$
B_{0}=D e^{-T y}
$$

Substituting (A.7) into Equation (A.6), dividing both sides of the equation by $D e^{-r T}$, and using the definition of leverage $(L)$ in (A.4), we can then write the yield to maturity as,

$$
y=r-\frac{1}{T} \ln \left[N\left(d_{2}\right)+\frac{N\left(-d_{1}\right)}{L}\right]
$$

and moving the risk-free rate, $r$, to the left-hand side we can write the credit spread as,

$$
S=y-r=-\frac{1}{T} \ln \left[N\left(d_{2}\right)+\frac{N\left(-d_{1}\right)}{L}\right]
$$

Equation (A.9) is Merton's model for the credit spread. Note that the spread depends only on maturity $(T)$, leverage $(L)$ and asset volatility $\left(\sigma_{A}\right)$.

\section{A.2. Sensitivity of CDS Price to Changes in Asset Volatility}

Now we want to see if the sensitivity of the spread to changes in asset volatility can be found with the model, i.e. we require an expression from the model for $\frac{\partial S}{\partial \sigma_{A}}$. 
Taking the first derivative of $S$, defined as in Equation (A.9), with respect to $\sigma_{A}$ we obtain:

$\frac{\partial S}{\partial \sigma_{A}}=-\frac{1}{T} \times \frac{\frac{\partial N\left(d_{2}\right)}{\partial \sigma_{A}}+\frac{\partial N\left(-d_{1}\right)}{\partial \sigma_{A}} \frac{1}{L}}{\left[N\left(d_{2}\right)+\frac{N\left(-d_{1}\right)}{L}\right]}=-\frac{1}{T} \times \frac{N^{\prime}\left(d_{2}\right) \frac{\partial d_{2}}{\partial \sigma_{A}}+N^{\prime}\left(d_{1}\right) \frac{\partial\left(-d_{1}\right)}{\partial \sigma_{A}} \frac{1}{L}}{\left[N\left(d_{2}\right)+\frac{N\left(-d_{1}\right)}{L}\right]}=\frac{N^{\prime}\left(d_{1}\right) \frac{\partial d_{1}}{\partial \sigma_{A}}-L N^{\prime}\left(d_{2}\right) \frac{\partial d_{2}}{\partial \sigma_{A}}}{T\left[N\left(-d_{1}\right)+L N\left(d_{2}\right)\right]}$

where $N^{\prime}\left(d_{1}\right)=\frac{1}{\sqrt{2 \pi}} e^{-\frac{d_{1}^{2}}{2}}$ and

$N^{\prime}\left(d_{2}\right)=\frac{1}{\sqrt{2 \pi}} e^{-\frac{d_{2}^{2}}{2}}$

We can show that:

$$
\frac{\partial d_{2}}{\partial \sigma_{A}}=\frac{\partial d_{1}}{\partial \sigma_{A}}-\sqrt{T}
$$

and

$$
N^{\prime}\left(d_{2}\right)=\frac{1}{L} N^{\prime}\left(d_{1}\right)
$$

Proof of Equation (A.11):

Given the definition of $d_{1}$,

$\frac{\partial d_{1}}{\partial \sigma_{A}}=\frac{\ln L}{\sigma_{A}{ }^{2} \sqrt{T}}+\frac{\sqrt{T}}{2}$

Similarly,

$\frac{\partial d_{2}}{\partial \sigma_{A}}=\frac{\ln L}{\sigma_{A}{ }^{2} \sqrt{T}}-\frac{\sqrt{T}}{2}$

Therefore,

$\frac{\partial d_{2}}{\partial \sigma_{A}}=\frac{\partial d_{1}}{\partial \sigma_{A}}-\sqrt{T}$

Proof of Equation (A.12):

We want to prove that

$\frac{1}{L}=\frac{N^{\prime}\left(d_{2}\right)}{N^{\prime}\left(d_{1}\right)}=\frac{e^{-\frac{d_{2}^{2}}{2}}}{e^{-\frac{d_{1}^{2}}{2}}}=e^{\frac{d_{1}^{2}-d_{2}^{2}}{2}}$

Equivalently, we want to show that

$-\ln L=\frac{d_{1}^{2}-d_{2}^{2}}{2}$

Since $d_{2}=d_{1}-\sigma^{A} \sqrt{T}$, we can rewrite the right-hand side as

$\frac{d_{1}^{2}-d_{2}^{2}}{2}=\frac{1}{2}\left(d_{1}+d_{2}\right)\left(d_{1}-d_{2}\right)=\frac{1}{2}\left(2 d_{1}-\sigma_{A} \sqrt{T}\right) \sigma_{A} \sqrt{T}=\left(d_{1}-\frac{\sigma_{A} \sqrt{T}}{2}\right) \sigma_{A} \sqrt{T}$

Recall that $d_{1}=\frac{-\ln (L)}{\sigma_{A} \sqrt{T}}+\frac{\sigma_{A} \sqrt{T}}{2}$. Thus:

$\left(\frac{-\ln L}{\sigma_{A} \sqrt{T}}+\frac{\sigma_{A} \sqrt{T}}{2}-\frac{\sigma_{A} \sqrt{T}}{2}\right) \sigma_{A} \sqrt{T}=-\ln L$ 
We can then substitute first (A.11) and then (A.12) into (A.10):

$$
\begin{aligned}
\frac{\partial S}{\partial \sigma_{A}} & =\frac{N^{\prime}\left(d_{1}\right) \frac{\partial d_{1}}{\partial \sigma_{A}}-L N^{\prime}\left(d_{2}\right) \frac{\partial d_{2}}{\partial \sigma_{A}}}{T\left[N\left(-d_{1}\right)+L N\left(d_{2}\right)\right]} \\
& =\frac{N^{\prime}\left(d_{1}\right) \frac{\partial d_{1}}{\partial \sigma_{A}}-L N^{\prime}\left(d_{2}\right) \frac{\partial d_{1}}{\partial \sigma_{A}}+L N^{\prime}\left(d_{2}\right) \sqrt{T}}{T\left[N\left(-d_{1}\right)+L N\left(d_{2}\right)\right]} \\
& =\frac{N^{\prime}\left(d_{1}\right) \frac{\partial d_{1}}{\partial \sigma_{A}}-N^{\prime}\left(d_{1}\right) \frac{\partial d_{1}}{\partial \sigma_{A}}+N^{\prime}\left(d_{1}\right) \sqrt{T}}{T\left[N\left(-d_{1}\right)+L N\left(d_{2}\right)\right]} \\
& =\frac{N^{\prime}\left(d_{1}\right) \sqrt{T}}{T\left[N\left(-d_{1}\right)+L N\left(d_{2}\right)\right]} \\
& =\frac{N^{\prime}\left(d_{1}\right)}{\sqrt{T}\left[N\left(-d_{1}\right)+L N\left(d_{2}\right)\right]}
\end{aligned}
$$

Equation (A.13) expresses the sensitivity of the spread to a change in asset volatility as a function of the same variables that affect the spread in (A.9), namely asset volatility, time to maturity and leverage. As an example, suppose $T=5, \sigma_{A}=0.50, r=0.05, L=0.10$. For a unit change in $\sigma_{A}$ the resulting change in spread from Equation (A.13) is 0.05922 . For a $1 \%$ change in $\sigma_{A}$ (from 0.50 to 0.51 ) the change in spread is therefore 0.0005922 , or 5.92 basis points. ${ }^{25}$ Moreover, from Equation (A.13) we can confirm that $\frac{\partial S}{\partial \sigma_{A}}$ is always positive.

In the paper our approach is to use $\partial S / \partial \sigma_{A}$ as an input to Merton's model, instead of using $\sigma_{A}$, thus allowing for a long tail in the distribution of $\sigma_{A}$. We can do this because $\partial S / \partial \sigma_{A}$ and $\sigma_{A}$ are monotonically related. However, we do not have an analytic solution for the model when using $\partial S / \partial \sigma_{A}$ as an input. Instead we proceed by adjusting $\sigma_{A}$ iteratively until the value of $\partial S / \partial \sigma_{A}$ from Equation (A.13) matches that required for a firm on a particular date. The model then gives a value for the CDS price based on the iteratively derived $\sigma_{A}$ that matches $\partial S / \partial \sigma_{A}$.

\section{A.3. Monotonic Relationship of $\partial S / \partial \sigma_{A}$ with $\sigma_{A}$ (and hence of $\partial S / \partial \sigma_{E}$ with $\sigma_{E}$ )}

We now demonstrate the positive monotonic relationship between $\partial S / \partial \sigma_{A}$ and $\sigma_{A}$, by showing that the second derivative of $S$ with respect to $\sigma_{A}$ is always always positive for the range of data in our sample. Because $\partial \sigma_{A}$ and $\partial \sigma_{E}$ are positively related via leverage, a positive monotonic relationship between $\partial S / \partial \sigma_{A}$ and $\sigma_{A}$ also implies a positive monotonic relationship between $\partial S / \partial \sigma_{E}$ and $\sigma_{E}$. In fact, from Equation (3') in sub-section 3.5 we know that:

${ }_{25}$ As a check on the equation, the spread at a volatility of 0.495 is 42.80 basis points and the spread at a volatility of 0.505 is 48.72 basis points, a change of 5.92 basis points. 
$\partial \sigma_{A}=(1-L)\left(\frac{\partial A}{\partial E}\right) \partial \sigma_{E}$

which can be re-written as $\partial \sigma_{A}=\phi \partial \sigma_{E}$

where $\phi=(1-L)\left(\frac{\partial A}{\partial E}\right)>0$ for firms which are not in default.

This implies: $\frac{\partial S}{\partial \sigma_{A}}=\frac{1}{\phi} \frac{\partial S}{\partial \sigma_{E}} \Rightarrow \frac{\partial^{2} S}{\partial \sigma_{A}{ }^{2}}=\frac{1}{\phi^{2}} \frac{\partial^{2} S}{\partial \sigma_{E}{ }^{2}} \Rightarrow$ If $\frac{\partial^{2} S}{\partial \sigma_{A}{ }^{2}}>0$ then $\frac{\partial^{2} S}{\partial \sigma_{E}{ }^{2}}>0$ (and vice-versa).

Note that since $S=y-r$, then $\frac{\partial S}{\partial \sigma_{A}}=\frac{\partial y}{\partial \sigma_{A}}$ and $\frac{\partial^{2} S}{\partial \sigma_{A}{ }^{2}}=\frac{\partial^{2} y}{\partial \sigma_{A}^{2}}$.

To simplify a little our calculations we start by rewriting Equation (A.7): $B_{0}=D e^{-T y}$.

Next, we note that the risky bond is equal in value to a risk-free bond with maturity $T$, less the value of a European put on the assets (held by the shareholders) with an exercise price equal to the face-value of the bond and exercise time $T$,

$$
B_{0}=D e^{-T r}-P_{0}
$$

Using (A.7) and (A.14) we have: $D e^{-T y}=D e^{-T r}-P_{0}$

Taking the first derivative of each side of the equation with respect to $\sigma_{A}$, we obtain: $D \frac{\partial e^{-T y}}{\partial \sigma_{A}}=-\frac{\partial P_{0}}{\partial \sigma_{A}}$

$-D T e^{-T y} \frac{\partial y}{\partial \sigma_{A}}=-\frac{\partial P_{0}}{\partial \sigma_{A}}$

$D T e^{-T y} \frac{\partial y}{\partial \sigma_{A}}=\frac{\partial P_{0}}{\partial \sigma_{A}}$

We re-write the first derivative of the spread $S$ with respect to the asset volatility $\sigma_{A}$ as:

$$
\frac{\partial S}{\partial \sigma_{A}}=\frac{\partial y}{\partial \sigma_{A}}=\left(\frac{1}{D T e^{-T y}}\right) \frac{\partial P_{0}}{\partial \sigma_{A}}
$$

Next, the second derivative of $S$ with respect to $\sigma_{A}$ is equal to:

$$
\begin{aligned}
\frac{\partial^{2} S}{\partial \sigma_{A}{ }^{2}}=\frac{\partial^{2} y}{\partial \sigma_{A}^{2}} & =\left(\frac{1}{D T e^{-T y}}\right) \frac{\partial^{2} P_{0}}{\partial \sigma_{A}^{2}}+\left(\frac{1}{D T}\right) T e^{T y} \frac{\partial y}{\partial \sigma_{A}} \frac{\partial P_{0}}{\partial \sigma_{A}} \\
& =\left(\frac{1}{D T e^{-T y}}\right) \frac{\partial^{2} P_{0}}{\partial \sigma_{A}^{2}}+\left(\frac{1}{D}\right) e^{T y} \frac{\partial P_{0}}{\partial \sigma_{A}}\left(\frac{1}{D T e^{-T y}}\right) \frac{\partial P_{0}}{\partial \sigma_{A}} \\
& =\left(\frac{1}{D T e^{-T y}}\right) \frac{\partial^{2} P_{0}}{\partial \sigma_{A}{ }^{2}}+\left(\frac{\partial P_{0}}{\partial \sigma_{A}}\right)^{2}\left(\frac{e^{T y}}{D}\right)\left(\frac{1}{T}\right)
\end{aligned}
$$

It can be shown that:

$$
\frac{\partial^{2} P_{0}}{\partial \sigma_{A}^{2}}=\left(\frac{\partial P_{0}}{\partial \sigma_{A}}\right)\left(\frac{d_{1} \times d_{2}}{\sigma_{A}}\right)
$$

Proof of Equation (A.17): 
First, using Equations (A.11) and (A.12), we demonstrate that:

$\frac{\partial P_{0}}{\partial \sigma_{A}}=V e g a=A_{0} N^{\prime}\left(d_{1}\right) \sqrt{T}=A_{0} \sqrt{T} \frac{1}{\sqrt{2 \pi}} e^{-\frac{d_{1}^{2}}{2}}$

We start by rewriting the put pricing equation:

$P_{0}=D e^{-T r} N\left(-d_{2}\right)-A_{0} N\left(-d_{1}\right)$

Then we take the first derivative of $P_{0}$ with respect to $\sigma_{A}$ :

$\frac{\partial P_{0}}{\partial \sigma_{A}}=V e g a=D e^{-T r} N^{\prime}\left(d_{2}\right) \frac{\partial\left(-d_{2}\right)}{\partial \sigma_{A}}-A_{0} N^{\prime}\left(d_{1}\right) \frac{\partial\left(-d_{1}\right)}{\partial \sigma_{A}}=A_{0} N^{\prime}\left(d_{1}\right) \frac{\partial d_{1}}{\partial \sigma_{A}}-D e^{-T r} N^{\prime}\left(d_{2}\right) \frac{\partial d_{2}}{\partial \sigma_{A}}$

Recall (A.11): $\frac{\partial d_{2}}{\partial \sigma_{A}}=\frac{\partial d_{1}}{\partial \sigma_{A}}-\sqrt{T}$

and from (A.12): $N^{\prime}\left(d_{2}\right)=\frac{1}{L} N^{\prime}\left(d_{1}\right) \Rightarrow A_{0} N^{\prime}\left(d_{1}\right)-D e^{-T r} N^{\prime}\left(d_{2}\right)=0$

Thus,

$\frac{\partial P_{0}}{\partial \sigma_{A}}=V e g a=A_{0} N^{\prime}\left(d_{1}\right) \frac{\partial d_{1}}{\partial \sigma_{A}}-D e^{-T r} N^{\prime}\left(d_{2}\right) \frac{\partial d_{2}}{\partial \sigma_{A}}$

$=A_{0} N^{\prime}\left(d_{1}\right) \frac{\partial d_{1}}{\partial \sigma_{A}}-D e^{-T r} N^{\prime}\left(d_{2}\right)\left(\frac{\partial d_{1}}{\partial \sigma_{A}}-\sqrt{T}\right)$

$=\underbrace{\left[A_{0} N^{\prime}\left(d_{1}\right)-D e^{-T r} N^{\prime}\left(d_{2}\right)\right]}_{=0} \frac{\partial d_{1}}{\partial \sigma_{A}}+\underbrace{D e^{-T r} N^{\prime}\left(d_{2}\right)}_{=A_{0} N^{\prime}\left(d_{1}\right)} \sqrt{T}$

$=A_{0} N^{\prime}\left(d_{1}\right) \sqrt{T}=A_{0} \frac{1}{\sqrt{2 \pi}} e^{-\frac{d_{1}^{2}}{2}} \sqrt{T}$

Q.E.D.

Next, we take the first derivative of $V e g a$ with respect to $\sigma_{A}$ :

$\frac{\partial^{2} P_{0}}{\partial \sigma_{A}{ }^{2}}=\frac{\partial V \text { ega }}{\partial \sigma_{A}}=\underbrace{\left[A_{0} \frac{1}{\sqrt{2 \pi}} e^{-\frac{d_{1}^{2}}{2}} \sqrt{T}\right]}_{=\frac{\partial P_{0}}{\partial \sigma_{A}}}\left[-d_{1} \times \frac{\partial d_{1}}{\partial \sigma_{A}}\right]=\frac{\partial P_{0}}{\partial \sigma_{A}}\left[-d_{1} \times \frac{\partial d_{1}}{\partial \sigma_{A}}\right]$

Let us focus on the second multiplier in the equation above: $-d_{1} \times \frac{\partial d_{1}}{\partial \sigma_{A}}$.

Recalling that $d_{1}=\frac{-\ln L}{\sigma_{A} \sqrt{T}}+\frac{\sigma_{A} \sqrt{T}}{2}$ and $-\frac{\partial d_{1}}{\partial \sigma_{A}}=\frac{-\ln L}{\sigma_{A}^{2} \sqrt{T}}-\frac{\sqrt{T}}{2}$,

$-d_{1} \times \frac{\partial d_{1}}{\partial \sigma_{A}}$ can be rewritten as:

$-d_{1} \times \frac{\partial d_{1}}{\partial \sigma_{A}}=d_{1} \times\left(-\frac{\partial d_{1}}{\partial \sigma_{A}} \times \frac{\sigma_{A}}{\sigma_{A}}\right)=\frac{1}{\sigma_{A}}\left(d_{1}\right) \underbrace{\left(\frac{-\ln L}{\sigma_{A} \sqrt{T}}-\frac{\sigma_{A} \sqrt{T}}{2}\right)}_{=d_{2}}=\frac{d_{1} \times d_{2}}{\sigma_{A}}$

Therefore: $\frac{\partial^{2} P_{0}}{\partial \sigma_{A}{ }^{2}}=\left(\frac{\partial P_{0}}{\partial \sigma_{A}}\right)\left(\frac{d_{1} \times d_{2}}{\sigma_{A}}\right)$

Q.E.D. 
Using Equations (A.15) and (A.17), we can now re-write Equation (A.16) as:

$$
\begin{aligned}
\frac{\partial^{2} S}{\partial \sigma_{A}{ }^{2}} & =\left(\frac{1}{D T e^{-T y}}\right)\left(\frac{\partial P_{0}}{\partial \sigma_{A}}\right)\left(\frac{d_{1} \times d_{2}}{\sigma_{A}}\right)+\left(\frac{1}{D e^{-T y}}\right)^{2}\left(\frac{1}{T}\right)\left(\frac{\partial P_{0}}{\partial \sigma_{A}}\right)\left(\frac{\partial P_{0}}{\partial \sigma_{A}}\right) \\
& =\underbrace{\left(\frac{1}{D T e^{-T y}}\right)\left(\frac{\partial P_{0}}{\partial \sigma_{A}}\right)}_{=\frac{\partial S}{\partial \sigma_{A}}} \times[\left(\frac{d_{1} \times d_{2}}{\sigma_{A}}\right)+\underbrace{\left.\left(\frac{\partial P_{0}}{\partial \sigma_{A}}\right)\left(\frac{1}{D e^{-T y}}\right)\right]}_{=T\left(\frac{\partial S}{\partial \sigma_{A}}\right)} \\
& =\left(\frac{\partial S}{\partial \sigma_{A}}\right) \times\left[\left(\frac{d_{1} \times d_{2}}{\sigma_{A}}\right)+T\left(\frac{\partial S}{\partial \sigma_{A}}\right)\right]
\end{aligned}
$$

In conclusion, since $\frac{\partial S}{\partial \sigma_{A}}>0$ always, we demonstrate that $\frac{\partial^{2} S}{\partial \sigma_{A}^{2}}>0$ if and only if: $\left(\frac{d_{1} \times d_{2}}{\sigma_{A}}\right)+T\left(\frac{\partial S}{\partial \sigma_{A}}\right)>0$.

We can restate this condition more simply as:

$\frac{\partial S}{\partial \sigma_{A}}>-\left(\frac{d_{1} \times d_{2}}{T \sigma_{A}}\right)$

We cannot observe $\frac{\partial S}{\partial \sigma_{A}}$; however, we know that: $\frac{\partial S}{\partial \sigma_{A}}=\frac{1}{\phi} \frac{\partial S}{\partial \sigma_{E}}$ where $\phi=(1-L)\left(\frac{\partial A}{\partial E}\right)$.

We re-state the condition for monotonicity as:

$\frac{\partial S}{\partial \sigma_{E}}>-(1-L) \frac{\partial A}{\partial E}\left(\frac{d_{1} \times d_{2}}{T \sigma_{A}}\right)=-(1-L) \frac{1}{N\left(d_{1}\right)}\left(\frac{d_{1} \times d_{2}}{T \sigma_{A}}\right)$.

We verify that this condition is always satisfied for values of $L$ and $\frac{\partial S}{\partial \sigma_{E}}$ estimated for our sample of data. Note that the condition depends also on the unobservable asset volatility $\sigma_{A}$, which we proxy respectively with:

(i) The implied asset volatility obtained from Equation (3):

$\sigma_{A}=\sigma_{E}(1-L) \frac{\partial A}{\partial E}=\sigma_{E}(1-L)\left(\frac{1}{N\left(d_{1}\right)}\right) ;$

(ii) The implied asset volatility estimated from inverting the Merton model (1974) using the market CDS premiums $\left(\sigma_{A}^{M K T}\right)$;

(iii) The implied asset volatility estimated from our M-Skew model $\left(\sigma_{A}^{M S K E W}\right)$.

We check that the monotonicity condition is satisfied for each case (i), (iii), and (iii), and for each firm over each week.

We cannot report the extensive results of the check for brevity (they remain available upon request); however, we report some significant MIN and MAX statistics:

\begin{tabular}{c|c|ccc}
\hline & $\frac{\partial S}{\partial \sigma_{E}}$ & \multicolumn{3}{|c}{$-(1-L) \frac{1}{N\left(d_{1}\right)}\left(\frac{d_{1} \times d_{2}}{T \sigma_{A}}\right)$} \\
\hline & & (i) & (ii) & (iii) \\
MIN & 3.149 & $-19,474$ & -3.124 & -2.153 \\
MAX & 11.239 & 0.008 & 0.028 & 0.006 \\
\hline
\end{tabular}


The important result is that in all three cases: $\operatorname{MIN}\left\{\frac{\partial S}{\partial \sigma_{E}}\right\}>M A X\left\{-(1-L) \frac{1}{N\left(d_{1}\right)}\left(\frac{d_{1} \times d_{2}}{T \sigma_{A}}\right)\right\}$.

This implies that:

$\frac{\partial S}{\partial \sigma_{E}}>-(1-L) \frac{1}{N\left(d_{1}\right)}\left(\frac{d_{1} \times d_{2}}{T \sigma_{A}}\right)=-\frac{1}{\phi}\left(\frac{d_{1} \times d_{2}}{T \sigma_{A}}\right)$ always.

Thus: $\phi \frac{\partial S}{\partial \sigma_{E}}=\frac{\partial S}{\partial \sigma_{A}}>-\left(\frac{d_{1} \times d_{2}}{T \sigma_{A}}\right) \Rightarrow$

$\left(\frac{d_{1} \times d_{2}}{\sigma_{A}}\right)+T\left(\frac{\partial S}{\partial \sigma_{A}}\right)>0 \Rightarrow$

$\frac{\partial^{2} S}{\partial \sigma_{A}{ }^{2}}=\left(\frac{\partial S}{\partial \sigma_{A}}\right) \times\left[\left(\frac{d_{1} \times d_{2}}{\sigma_{A}}\right)+T\left(\frac{\partial S}{\partial \sigma_{A}}\right)\right]>0$ always.

Q.E.D. 


\section{Appendix B. Firms in the Sample}

\begin{tabular}{|c|c|c|c|}
\hline Company Name & Ticker & Sector & Industry \\
\hline Alcoa Inc & AA & Basic Materials & Aluminium \\
\hline Anadarko Petroleum Corp & $\mathrm{APC}$ & Basic Materials & Independent Oil \& Gas \\
\hline Arrow Electronics Inc & ARW & Services & Electronics Wholesale \\
\hline Boeing Co & $\mathrm{BA}$ & Industrial Goods & Aerospace/Defence Products \&Services \\
\hline Burlington Northern Santa Fe LLC & $\mathrm{BNI}$ & Services & Railroads \\
\hline Campbell Soup Co & $\mathrm{CPB}$ & Consumer Goods & Processed \& Packaged Goods \\
\hline Caterpillar Inc & CAT & Industrial Goods & Farm \& Construction Machinery \\
\hline Computer Sciences Corp & $\mathrm{CSC}$ & Technology & Information Technology Services \\
\hline ConAgra Foods Inc & $\mathrm{CAG}$ & Consumer Goods & Processed \& Packaged Goods \\
\hline ConocoPhillips & $\mathrm{COP}$ & Basic Materials & Major Integrated Oil \& Gas \\
\hline Deere \& Co & $\mathrm{DE}$ & Industrial Goods & Farm \& Construction Machinery \\
\hline Devon Energy Corp & DVN & Basic Materials & Independent Oil \& Gas \\
\hline Dominion Resources Inc/VA & $\mathrm{D}$ & Utilities & Electric Utilities \\
\hline Dow Chemical Co/The & DOW & Basic Materials & Chemicals - Major Diversified \\
\hline Duke Energy Corp & DUK & Utilities & Electric Utilities \\
\hline Eastman Chemical Co & EMN & Basic Materials & Chemicals - Major Diversified \\
\hline EI du Pont de Nemours \& Co & DD & Basic Materials & Chemicals - Major Diversified \\
\hline General Mills Inc & GIS & Consumer Goods & Processed \& Packaged Goods \\
\hline Goodrich Corp & GR & Industrial Goods & Aerospace/Defence Products \&Services \\
\hline Halliburton Co & HAL & Basic Materials & Oil \& Gas Equipment \& Services \\
\hline Hewlett-Packard Co & HPQ & Technology & Diversified Computer Systems \\
\hline Honeywell International Inc & $\mathrm{HON}$ & Industrial Goods & Aerospace/Defence Products \&Services \\
\hline IBM Corp & IBM & Technology & Diversified Computer Systems \\
\hline Kraft Foods Inc & KFT & Consumer Goods & Food - Major Diversified \\
\hline Kroger Co/The & $\mathrm{KR}$ & Services & Grocery Stores \\
\hline Lockheed Martin Corp & LMT & Industrial Goods & Aerospace/Defence Products \&Services \\
\hline Ltd Brands Inc & LTD & Services & Apparel Stores \\
\hline Marriott International Inc/DE & MAR & Services & Lodging and Restaurants \\
\hline McDonald's Corp & MCD & Services & Lodging and Restaurants \\
\hline Motorola Inc & MOT & Technology & Diversified Communication Services \\
\hline Newell Rubbermaid Inc & NWL & Consumer Goods & Housewares \& Accessories \\
\hline Nordstrom Inc & JWN & Services & Apparel Stores \\
\hline Norfolk Southern Corp & NSC & Services & Railroads \\
\hline Northrop Grumman Corp & NOC & Industrial Goods & Aerospace/Defence - Major Diversified \\
\hline Omnicom Group Inc & $\mathrm{OMC}$ & Services & Advertising Agencies \\
\hline Progress Energy Inc & PGN & Utilities & Electric Utilities \\
\hline Raytheon Co & RTN & Industrial Goods & Aerospace/Defence - Major Diversified \\
\hline Safeway Inc & SWY & Services & Grocery Stores \\
\hline Valero Energy Corp & VLO & Basic Materials & Oil \& Gas Refining \& Marketing \\
\hline Walt Disney Co/The & DIS & Services & Entertainment - Diversified \\
\hline
\end{tabular}




\section{Appendix C.}

\section{Leverage and the Panel Regression}

When estimating the relationship between the CDS price and equity volatility, we do not allow $\frac{\partial S}{\partial \sigma_{E}}$ to vary across different leverages. We make this judgement about the specification from the insights of the Merton model.

Let us consider again (graphically) how in the Merton model the sensitivity of the CDS price to asset volatility $\frac{\partial S}{\partial \sigma_{A}}$ relates to asset volatility $\sigma_{A}$ at different leverage levels. This is shown in Figure C.1 (for a 5-year CDS contract). We can clearly observe a larger $\frac{\partial S}{\partial \sigma_{A}}$ at higher leverage levels.

Figure C.1: $\frac{\partial S}{\partial \sigma_{A}}$ and $\sigma_{A}$ at Different Leverage Levels

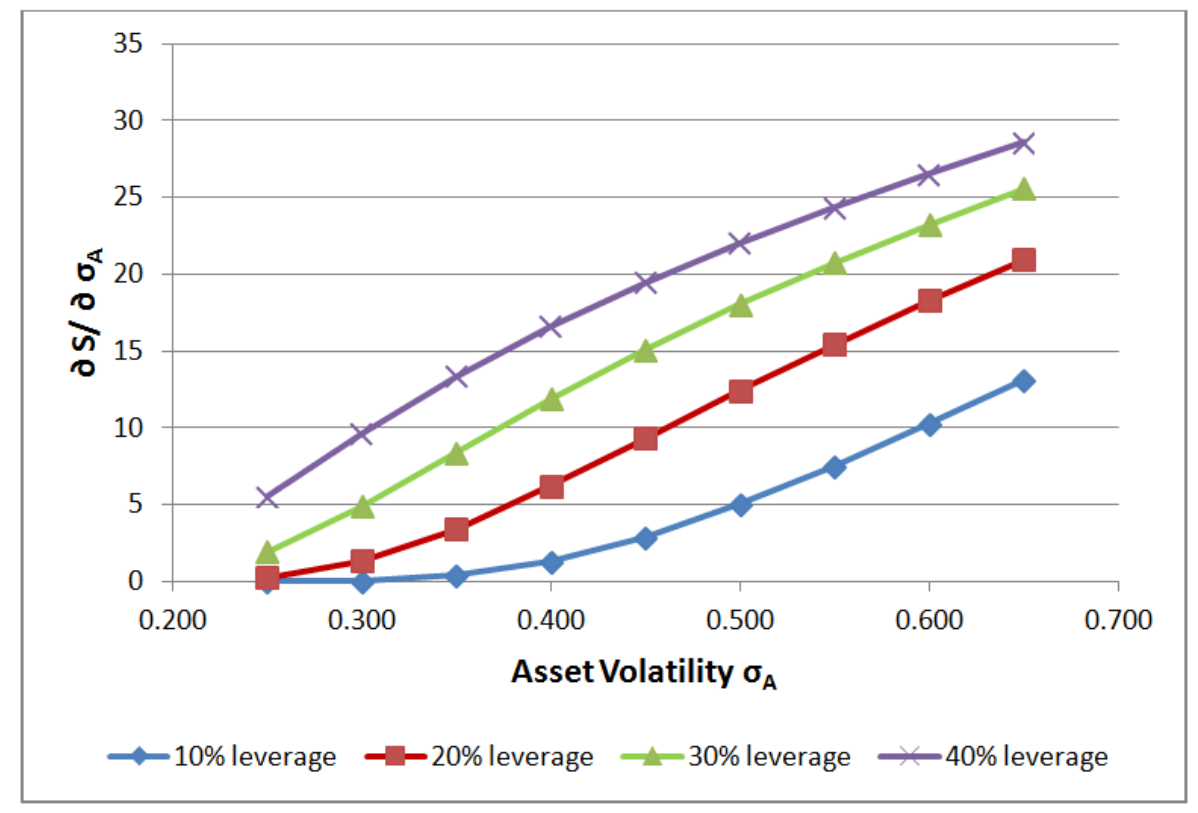

However, if we compute the sensitivity of the CDS price to equity volatility $\left(\frac{\partial S}{\partial \sigma_{E}}\right)$ against equity volatility $\left(\sigma_{E}\right)$ at different leverage levels, we obtain Figure C.2.

Figure C.2 shows that $\frac{\partial S}{\partial \sigma_{E}}$ is rather similar for the three higher levels of leverage shown, i.e. from $20 \%$ upwards. The $\frac{\partial S}{\partial \sigma_{E}}$ at $10 \%$ leverage is a little smaller than the others, especially for a middle range of equity volatilities between $45 \%$ and $65 \%$. 
Figure C.2: $\frac{\partial S}{\partial \sigma_{E}}$ and $\sigma_{E}$ at Different Leverage Levels

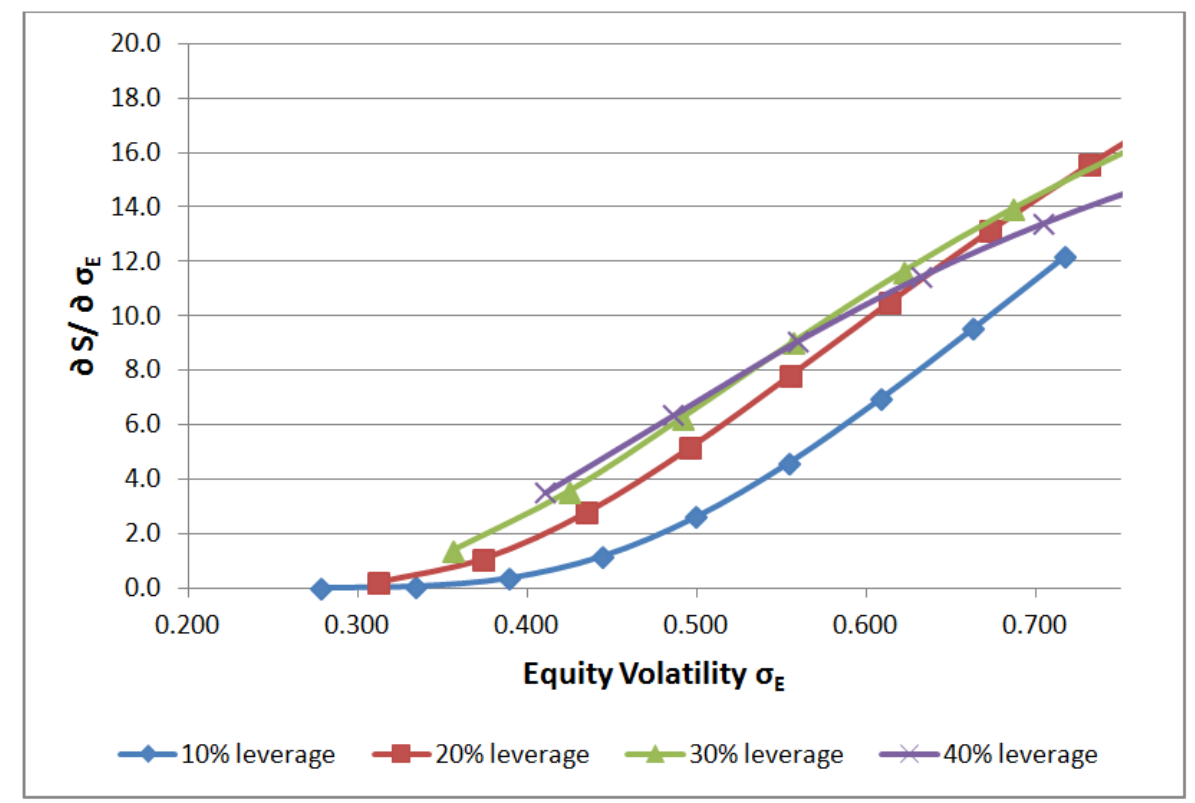

We have experimented with panel regressions which allow for different $\frac{\partial S}{\partial \sigma_{E}}$ values at different leverage levels, but with limited success. It proves very difficult to separate the effect of equity volatility from that of leverage. We therefore choose a simple specification which assumes that leverage has an impact on the CDS price, but has no impact on $\frac{\partial S}{\partial \sigma_{E}}$. The chosen specification is equivalent to fitting a single line to the four plots in Figure C.2.

Finally, it should be emphasised that we are not ignoring leverage. Not only is it (of course) a very important variable in the Merton model, but it also affects the $\frac{\partial S}{\partial \sigma_{A}}$ value for a firm (which is calculated by adjusting the estimated $\frac{\partial S}{\partial \sigma_{E}}$ : see Equation (7) of this paper). ${ }^{26}$

${ }^{26}$ It should also be noted that the values of equity volatility considered in the above analysis with the model are in the risk-neutral $(\mathrm{Q})$ domain with a horizon of five years, $\sigma_{E, Q, 5}$, whereas the panel regressions utilise equity volatility observed in the physical $(\mathrm{P})$ domain with a short-run horizon, $\sigma_{E, P, d}$. We are assuming that equity volatilities measured in the two domains move together (see discussion in section 3.2). 